\title{
Virusinfektionen der Haut
}

Allgemeines. Viren, die Hautinfekte oder Systeminfekte mit Hautsymptomatik erzeugen können, sind sehr zahlreich, und die klinischen Erscheinungsbilder sehr verschiedenartig (Abb.67). Grundsätzlich kann die Infektion der Haut über 3 Wege erfolgen: direkte exogene Infektion (Beispiel: Viruswarzen), Besiedelung aus einem extrakutanen Fokus (Herpes simplex, zoster) und hämatogene Dissemination bei Systeminfektionen (exanthematische Viruskrankheiten).

Die Diagnostik von Viruskrankheiten der Haut beruht vorwiegend auf klinischen Kriterien und ist häufig einfach, da viele klinische Bilder pathognomonisch sind. Gelingt die Diagnose nicht auf morphologischer Basis, ist man auf kompliziertere und zeitaufwendigere Techniken angewiesen: Kultur (Speziallabors vorbehalten), Serologie (langwierig, da definitive Diagnosen meist erst durch den Titerverlauf gestellt werden können), morphologischer Nachweis im Elektronenmikroskop (nicht immer anwendbar). Ein wertvoller Schnelltest, leider aber nur bei wenigen Krankheiten anwendbar, ist der Tzanck-Test (zytologischer Nachweis von Virusriesenzellen bei Erkrankungen durch die Herpesvirusgruppe).

\section{Exanthematische Viruskrankheiten}

\section{Masern (Morbilli)}

Erreger. Paramyxovirus (RNS-Virus); gegen Hitze, UV-Licht und verschiedene Chemikalien empfindlich. Ansteckung durch Tröpfcheninfektion.

Allgemeines. Weltweit, hauptsächlich bei Kindern vorkommende Infektionskrankheit mit nahezu 100\%iger Kontagiosität bei der nichtimmunen Bevölkerung. Säuglinge unter 4 Monaten sind durch materne Antikörper geschützt. Masern treten saisonal gehäuft auf (Höhepunkt zu Frühlingsbeginn).

Klinisches Bild. Inkubationszeit etwa 10 Tage, daran anschließend Prodrome (Fieber, Rhinitis, Konjunktivitis, Husten) über etwa 4 Tage und schließlich Beginn des Exanthems, das nach einer knappen Woche spontan abklingt. Das Exanthem besteht aus schnell konfluierenden makulopapulösen Erythemen, die im Gesicht beginnen und sich rasch auf Rumpf und schließlich Extremitäten ausbreiten; innerhalb weniger Tage ist der gesamte Körper 


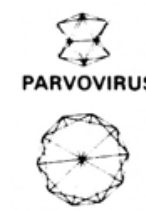

PAPOVAVIRUS

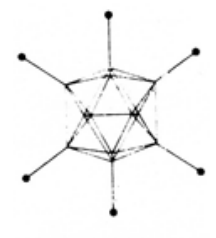

ADENOVIRUS

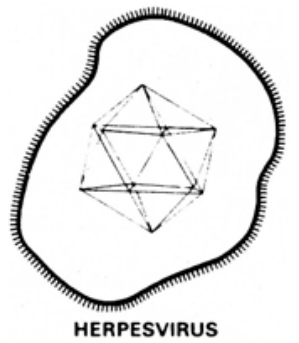

RNS Viren
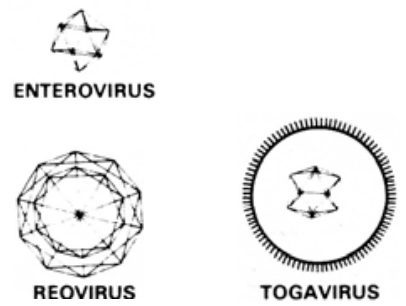
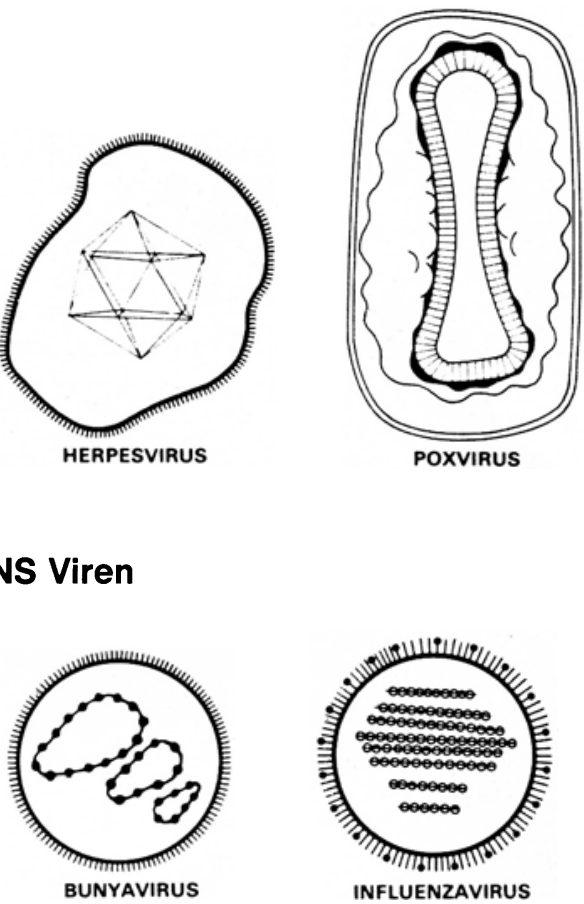

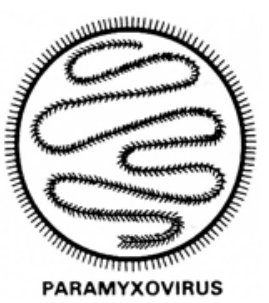

PARAMYXOVIRUS
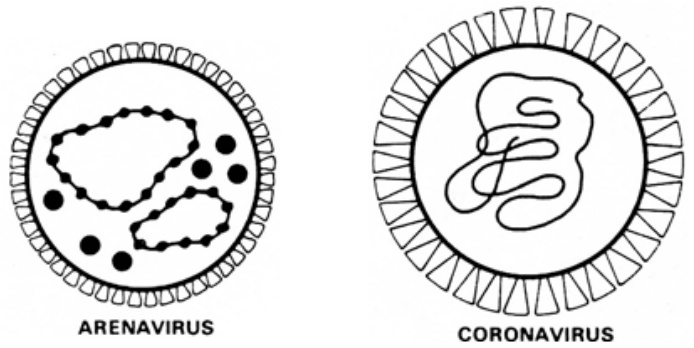
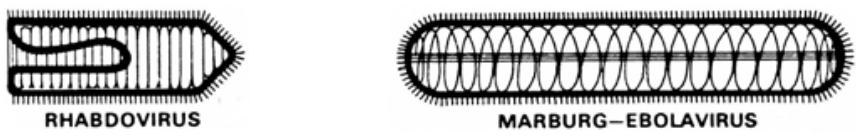

Abb. 67. Morphologie wichtiger Virusfamilien. Erreger dermatologischer Krankheiten sind: Parvovirus (Erythema infectiosum), Papovavirus (Viruswarzen), Herpesvirus, Poxvirus (= Pockenvirus), Enterovirus (Coxsackie-, ECHO-Virus-Infektionen), Togavirus (Rubeolen), Paramyxovirus (Masern) (Aus Palmer, 1982) 
ergriffen. In der Mundhöhle finden sich, beginnend 1-2 Tage vor Ausbruch des Exanthems, die diagnostisch relevanten Koplik-Flecke (multiple, hellrote, stecknadelkopfgroße Flecke mit weißlichem Zentrum, v.a. an der Wangenschleimhaut gegenüber dem 2. Molaren). Gleichzeitig damit kommen auch die Systemzeichen (Fieber, Rhinitis, Husten, Konjunktivitis etc.) zum Höhepunkt. Anschließend relativ schnelle Rückbildung des Exanthems in der Reihenfolge des Auftretens, meist unter feiner pityriasiformer Schuppung. Masern hinterlassen lebenslange Immunität. Nicht selten besitzen die erythematösen Läsionen eine milde Purpurakomponente. Eine Sonderform mit schwerer Purpura und schwerer Systemtoxizität (hohe Mortalität!) sind die hämorrhagischen Masern („schwarze Masern“).

Komplikationen. Masernenzephalitis (etwa 1 auf 1800 Fälle; führt zwar selten zum Tod, meist aber zu Hirnschaden), thrombozytopenische Purpura. Indirekte Folge von Masern: durch die nach Masern charakteristische vorübergehende Verschlechterung der Immunitätslage höhere Inzidenz von Infektionskrankheiten (Pneumonien, Otitis media, Exazerbationen von präexistenter Tuberkulose etc.).

Seit Einführung der Masernimpfung kommen atypische Masernverläufe mit uncharakteristischen makulourtikariellen Exanthemen vor.

Labor. Leukopenie, positive serologische Tests (neutralisierende, hämagglutinierende und komplementbindende Antikörper).

Therapie. Hyperimmunglobulin in schweren Fällen.

Prognose. Mortalität am höchsten bei Säuglingen (etwa 1 auf 30000 Fälle). Ausrottungsprogramm der WHO wird z.Z. durchgeführt.

\section{Röteln (Rubeolen)}

\section{Erreger. Togavirus (RNS-Virus)}

Allgemeines. Weltweite, vorwiegend bei Kindern, aber auch jungen Erwachsenen vorkommende Infektionskrankheit, die zu periodischen Epidemien (etwa 5jährige Abstände) neigt. Übertragung durch den Respirationstrakt (Tröpfcheninfektion).

Klinisches Bild. Inkubationszeit 2 Wochen, anschließend Prodrome (Fieber, Kopfschmerzen, Konjunktivitis, Rhinitis, Husten; bei Erwachsenen viel stärker ausgeprägt als bei Kindern!). Das Exanthem besteht aus diskreten, hellroten Erythemen, die im Gesicht beginnen, sich schnell auf Rumpf und Extremitäten ausbreiten. Konfluenz ist kein typisches Merkmal; gelegentlich am Rumpf. Charakteristischer Befund: generalisierte Lymphknotenschwellung mit exzessiver Betonung der subokzipitalen, retroaurikulären und zervikalen Lymphknoten. Begleitsymptomatik: Splenomegalie, Arthralgien.

Komplikationen. Enzephalitis und thrombozytopenische Purpura; beides ist sehr selten und milder als bei Masern. 
Labor. Mäßige Leukopenie, positive serologische Tests (neutralisierende, komplementfixierende und hämagglutinierende Antikörper).

Prognose. Grundsätzlich gut, der Infektion folgt eine lebenslange Immunität. Rubeolenvakzination wird weniger wegen der Krankheit selbst als wegen der Rubeolenembryopathie durchgeführt.

Rötelembryopathie. Bei Rubeoleninfektion der Mutter während des ersten Trimenons kommt es in 50\% der Fälle zu ausgedehnten devastierenden Mißbildungen der Frucht.

\section{Rubeoliforme Virusexantheme}

Allgemeines. Aus der obigen Beschreibung geht hervor, daß das Rubeolenexanthem von vergleichsweise wenig charakteristischer Morphologie ist; es ist also nicht verwunderlich, daß uncharakteristische Exantheme verschiedener Art (Arzneimittelexantheme, Virusexantheme) häufig als „rubeoliform“ beschrieben werden.

Eine ganze Reihe von Viren kann fieberhafte exanthemische Krankheitsbilder mit Ähnlichkeit mit Röteln hervorrufen; hauptsächlichste Erreger: Coxsackie-Viren (insbesondere Coxsackie B1 und B5), ECHO-Viren (insbesondere Echo 9), sowie das Epstein-Barr-Virus (infektiöse Mononukleose).

Die virale Genese solcher Exantheme wird durch die typischen Symptome von Prodromen, katarrhalischen Erscheinungen, Lymphadenopathie, Fieber und oft auch milder Leukopenie nahegelegt; im Unterschied zu den Rubeolen ist jedoch die typische Schwellung der Nackenlymphknoten sehr gering ausgeprägt, und auch die katarrhalische Seitensymptomatik ist weniger auffällig. Die Unterscheidung dieser Krankheitsbilder ist meist erst retrospektiv durch die Viruskultur (aus der Rachenspülflüssigkeit) und serologisch möglich.

\section{Erythema infectiosum (Ringelröteln)}

Erreger. Ein Parvovirus (RNS-Virus).

Allgemeines. Weltweite, hauptsächlich Kinder und gelegentlich jüngere Erwachsene betreffende Infektionskrankheit mit Neigung zu epidemischem Auftreten. Besonders häufig in Zentraleuropa! Ansteckung durch den Respirationstrakt (Tröpfcheninfektion).

Klinisches Bild. Inkubationszeit 14-18 Tage, Prodrome: Fieber, Arthralgien. Das Exanthem beginnt mit dunkelroten Knötchen an den Wangen, die schnell konfluieren und eine wohl abgegrenzte plattenartige Rötung ergeben (treffender Vergleich: „Ohrfeigengesicht “). Anschließend tritt ein makulopapulöses Exanthem mit auffallenden, bizarren, streifenförmigen und kringeligen Figuren an Oberarmen und Oberschenkeln auf und breitet sich zentripetal über den Rumpf aus (Abb.68). Nach 1-3 Wochen spontanes Abklingen. 


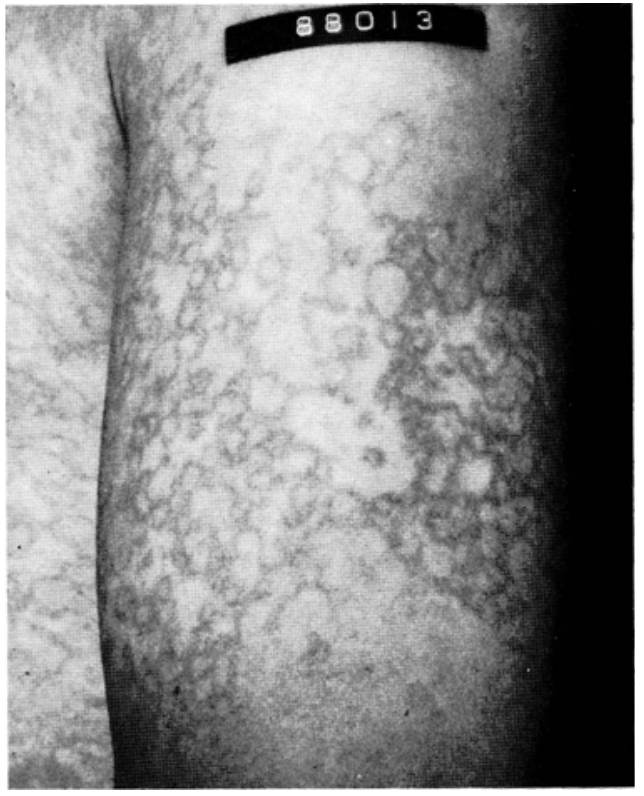

Abb. 68. Ringelröteln. Charakteristische kringelige Figuren, durch zentrale Abblassung makulourtikarieller Effloreszenzen entstanden

Labor. Serologischer Nachweis (bisher nur in Speziallabors). Leukopenie, mit Einsetzen des Exanthems milde Leukozytose. Reticulocytopenie, Sinken des Hämoglobins.

- Merke: bei Patienten mit chronischer hämolytischer Anämie führt die Parvovirusinfektion zur aplastischen Krise.

\section{Exanthema subitum (Roseola infantum)}

Allgemeines. Weltweit verbreitet, relativ selten. Nicht allseits als Krankheitseinheit anerkannt. Betroffen sind vor allem Säuglinge und Kleinkinder. Kontagiosität relativ gering (familiäre Häufung selten, keine Epidemien), doch kommt es zu saisonaler Häufung im Frühjahr und Herbst. Erreger bislang nicht isoliert.

Klinisches Bild. Nach einer Inkubationszeit von etwa 2 Wochen stellt sich hohes $\left(40^{\circ} \mathrm{C}\right), 3-5$ Tage andauerndes Fieber ein, das plötzlich mit dem Eintritt des Exanthems abflaut. Letzteres besteht aus kleinen, nicht konfluierenden Erythemen (Rumpf). Das Exanthem besteht ca. einen Tag und verschwindet dann spontan ohne Abschuppung.

Begleitsymptomatik. Subokzipitale Lymphknotenvergrößerung, keine Beeinträchtigung des Allgemeinzustandes.

Labor. Leukopenie, serologische Tests nicht bekannt. 


\section{Hand-foot-mouth-disease}

Erreger. Coxsackie-Virus A 16.

Allgemeines. Weltweite, hauptsächlich Kinder unter 10 Jahren ergreifende Infektionskrankheit. Die Infektion erfolgt durch den Gastrointestinaltrakt. Übertragung durch Abwässer (Coxsackie-Viren sind Enteroviren). Epidemisches Auftreten in der warmen Jahreszeit.

Klinisches Bild. Inkubationszeit 3-6 Tage; Prodrome sind kurz (1 Tag; Fieber, Bauchschmerzen). Das Exanthem beginnt mit erythematösen kleinen Läsionen an Zunge, hartem Gaumen und Wangenschleimhaut (meistens zwischen 5 und 10 Läsionen), die sich schnell in kurzlebige Bläschen und dann in seichte, schmierig belegte Ulzera mit erythematösem Halo umwandeln. Diese Läsionen sind sehr schmerzhaft, machen das Essen schwierig, sind aber selbstlimitiert (Spontanheilung in etwa 1 Woche). Die Läsionen sehen chronisch-rezidivierenden Aphthen und Läsionen des Erythema multiforme ähnlich. Gleichzeitig oder kurz darauf die akralen Läsionen: meistens zahlreich, vorwiegend an den Dorsalseiten von Händen und Füßen bzw. von Fingern und Zehen; die Läsionen sind ähnlich den Schleimhautläsionen: erythematöse Papeln, Umwandlung in Vesikeln und Krusten. Zusätzlich finden sich uncharakteristische makulopapulöse Läsionen an den Hinterbacken (fakultativ).

Begleiterscheinungen. Milde oder fehlen gänzlich; nur in Ausnahmefällen Fieber, Durchfall und Arthralgien.

Verlauf und Prognose. Abheilung nach etwa 1 Woche.

Labor. Serologischer Nachweis; Antikörper sind jedoch nur während der akuten Phase nachweisbar und verschwinden schon in der Rekonvaleszenz!

\section{Herpangina}

Erreger. Verschiedene Typen von Coxsackie-A-Virus (2-6, 8 und 10).

Allgemeines. Charakteristische Infektionskrankheit von weltweitem Vorkommen (hauptsächlich bei Kindern).

Klinisches Bild. Aus voller Gesundheit auftretendes hohes Fieber (bis über $40{ }^{\circ} \mathrm{C}$ ), das mehrere Tage dauert und von Kopfweh, Arthralgien, Nackenschmerzen, Erbrechen und Bauchschmerzen begleitet wird; manchmal Krämpfe! Gleichzeitig Entstehung von multiplen, grau-weißen, papulovesikulösen kleinen Läsionen, die in charakteristischer Weise an weichem Gaumen und Tonsillennischen ringartig den Schlund umgeben und sich in oberflächliche, schmierig belegte schmerzhafte Geschwüre umwandeln. Diffuse Rachenrötung.

Labor. Leukozytose; selten: Thrombopenie. Serologischer Nachweis. 
Prognose. Selbstlimitierte, gutartige Krankheit; dauert selten länger als 1 Woche.

\section{Pocken (Variola vera)}

Erreger. Poxvirus variolae, ein quaderförmiges DNS-Virus.

Allgemeines. Pocken stellten früher eine weltweit verbreitete, epidemische Infektionskrankheit mit hoher Mortalität und einem Spektrum klinischer Unterformen dar, deren Ausbreitungsgebiete v.a. in Afrika und im indischen Subkontinent lagen. Durch eine großangelegte Impfkampagne der WHO wurde diese Krankheit Ende der 70er Jahre ausgerottet; da Tierreservoirs von Poxvirus variolae nicht bestehen, ist nicht wieder mit einem Aufflackern der Krankheit zu rechnen. Es handelte sich um eine exanthematische, mit schwersten Systemmanifestationen einhergehende Krankheit, die sich zuerst durch makulopapulöse, später pustulöse, dichtsitzende konfluierende Läsionen am gesamten Körper mit Prädilektion des Rumpfes auszeichnete. Im Gegensatz zu vesikopustulösen Eruptionen anderer Natur (z. B. schwerverlaufende Varizellen) sind diese Blasen genabelt. Die Prognose bei Variola hing von der Verlaufsform ab, die durchschnittliche Mortalität lag bei etwa $25 \%$; foudroyante und hämorrhagische Pocken verliefen fast stets tödlich.

Differentialdiagnose. Da Pocken als ausgerottet gelten, fällt eine Differentialdiagnose theoretisch aus; schwer verlaufende Fälle von Varizellen (etwa bei immundefizienten Individuen) können echten Pocken manchmal täuschend ähnlich sehen. In solchen Fällen müssen daher die Pocken immer noch durch geeignete Tests ausgeschlossen werden, wobei sich der behandelnde Arzt darüber im klaren sein muß, daß schon Pockenverdacht meldepflichtig ist und die Meldung erhebliche Konsequenzen nach sich zieht (Verhängung der Quarantäne bis zum zweifelsfreien Ausschluß der Pocken). Die Nachweistechniken von Pocken dürfen daher noch nicht vergessen werden; sie umfassen den

- zytologischen Abstrich aus dem Bläscheninhalt (zeigt eosinophile Einschlußkörperchen, die sogenannten Guarnierschen Einschlußkörperchen),

- den elektronenmikroskopischen Nachweis aus dem negative-stain-Präparat (typische Quaderviren, DD. gegenüber anderen Pocken-Viren allerdings nur schwer möglich) und die

- Viruskultur aus dem Blaseninhalt und dessen Identifikation mittels spezifischer Antiseren.

Hautkomplikationen der Pockenimpfung. Die Impfung wurde mit einer Lebendvakzine, einem attenuierten Kuhpockenvirus (Vacciniavirus) durchgeführt und war in Österreich bis 1.Januar 1980 Pflicht; seit diesem Zeitpunkt wird sie nur noch auf Verlangen, d.h. außerordentlich selten durchgeführt. Die Impfung erfolgte an Kleinkindern (während des auf die Geburt folgenden Kalenderjahrs) und bestand aus der lokalen Aufbringung des Impfstoffes in 2 oberflächliche Hautschnitte; in diesen entwickelte sich bei normalem 
Verlauf je eine genabelte Pustel, die sich in eine Kruste umwandelte und schließlich abgestoßen wurde. Die Komplikationen der Impfung waren mannigfaltig: Die Impfreaktion konnte besonders intensiv sein und nekrotisieren, was gewöhnlich auch mit einer lokalen Ausbreitung durch Satellitenpusteln einherging (Vaccinia gangraenosa, Vaccinia progressiva). Das Vacciniavirus wurde ferner nicht selten durch Schmierinfektion an andere Körperstellen übertragen (Vaccinia inoculata), wobei die Prädilektionsstellen das Gesicht und die Genitalgegend waren. Schließlich konnte die Vaccinia auch an noch nicht geimpfte Personen der Umgebung übertragen werden (Vaccinia translata).

Das Vacciniavirus hat eine besondere Prädilektion für präexistente Hautläsionen, insbesondere Ekzeme. Bei Ekzematikern (Neurodermitis!) ist die Pokkenschutzimpfung daher kontraindiziert. Die Superinfektion einer Neurodermitis erfolgt gewöhnlich durch Schmierinfektion; das resultierende sog. Eczema vaccinatum ist eine hochfieberhafte schwere Systemkrankheit, die durch generalisierte Aussaat von Vaccinialäsionen gekennzeichnet ist und narbig abheilt. Durch Virämie kann es in seltenen Fällen zu Befall innerer Organe kommen, wobei die gefürchtetste Komplikation die Vacciniaenzephalitis ist.

\section{Kuhpocken}

Erreger. Kuhpockenvirus, ein morphologisch mit dem Pockenvirus identisches, serologisch jedoch verschiedenes Virus.

Allgemeines. Weit verbreitete Infektionskrankheit der Rinder, die nur fakultativ auf den Menschen übergreift und hauptsächlich berufsbedingt erworben wird (Melker).

Klinisches Bild. Die Krankheit manifestiert sich nach einer etwa einwöchigen Inkubationszeit als multiple vesikulopustulöse Läsionen v.a. an Händen und im Gesicht, begleitet von Fieber, Lymphangitis und Lymphadenitis. Die Krankheit kommt spontan nach mehrwöchigem Verlauf zum Abklingen.

\section{Lokale Virusinfektionen}

\section{Melkerknoten}

Erreger. Paravacciniavirus, ein Pockenvirus (siehe Abb.78a, S.223).

Allgemeines. Weltweit verbreitete Virusinfektion der Rinder (chronisch-rezidivierende papulokrustöse Läsionen v.a. an den Eutern), die auf Menschen übertragen werden kann. Die Übertragung erfolgt durch direkten Kontakt und ist daher meist berufsbedingt (Melker, Schlachthausarbeiter etc.).

Klinisches Bild (Abb.69). Meist nur eine oder wenige Läsionen; typischerweise ein nur wenig schmerzhafter, flacher, geröteter Knoten, der im Zentrum 


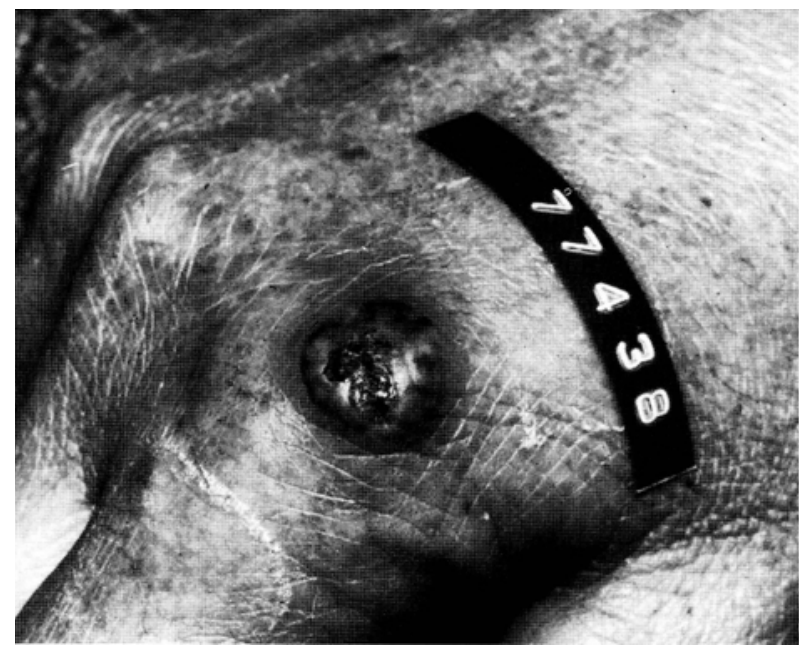

Abb. 69. Melkerknoten. Ein derber, hämorrhagisch und zentral exulzerierter Knoten

vesikulös, erosiv, krustös wird und nach etwa 4-6 Wochen spontan abheilt. Lymphknotenschwellung und Allgemeinerscheinungen fehlen fast immer. Inkubationszeit etwa 1 Woche.

Histologie. Psoriasiforme Hyperplasie der Epidermis mit Spongiose und ballonierender Degeneration.

Prognose. Die Infektion hinterläßt meist lebenslange Immunität.

\section{Orf (Ecthyma contagiosum)}

Erreger. Ein Pockenvirus.

Allgemeines. Virale Infektionskrankheit von Schafen, weltweit verbreitet und relativ häufig, die sich durch squamokrustöse und ulzeröse Veränderungen um Nase und Maul manifestiert; Virus auf den Menschen übertragbar (fast stets beruflich bedingt), ruft melkerknotenähnliche Veränderungen hervor.

Klinisches Bild. Gewöhnlich nur eine, manchmal einige Läsionen vor allem an den Händen. Beginnt mit geröteten Knoten, die im weiteren Verlauf erosiv, krustig und papillomatös werden. Milde Lymphknotenvergrößerung ist häufig, Allgemeinsymptome selten. Spontanheilung nach etwa einem Monat.

Histologie. Ausgeprägte pseudoepitheliomatöse Hyperplasie; auch klinisch können manche Läsionen durch fungierenden Aufbau tumorähnlich aussehen. 
Differentialdiagnose. Plattenepithelkarzinom, Melkerknoten, Granuloma pyogenicum.

\section{Molluscum contagiosum}

Erreger. Ein durch seine Größe ausgezeichnetes Pockenvirus.

Allgemeines. Häufige, benigne Virusinfektion der Haut, hauptsächlich bei Kindern; weltweite Verbreitung, Übertragung wahrscheinlich durch Schmierinfektion. Knaben sind häufiger betroffen als Mädchen.

Klinisches Bild (Abb. 70). Die Initialläsion ist eine kleine, weiche, hautfarbene Papel, die langsam anwächst, aber nur in seltenen Fällen größer als $5 \mathrm{~mm}$ wird. Die Läsion wirkt manchmal „durchscheinend“, zystisch, besitzt eine glänzende Oberfläche und einen zentralen Krater; bei Quetschen kann aus

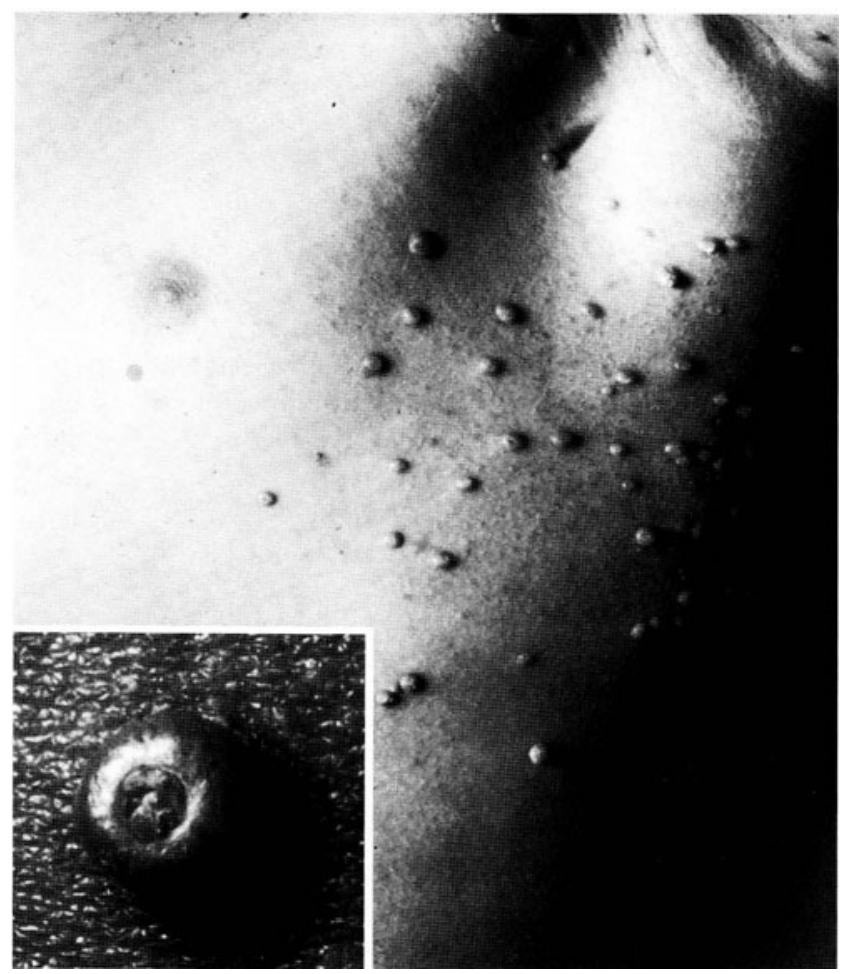

Abb. 70. Mollusca contagiosa: kugelige, wächsern-transparente Läsionen mit zentralem Porus. Im Porus erkennt man den zum Ausdrücken bereiten Molluscumbrei (Inset) 
diesem ein weißlicher talgartiger Brei exprimiert werden („Molluscumbrei“); diese diagnostische Manipulation ist gleichzeitig auch die Therapie einer Einzelläsion. Die Zahl der Läsionen reicht von einigen bis zu hunderten, die den gesamten Körper und (selten!) auch die Schleimhäute bedecken können. Hauptlokalisationen: Gesicht, große Beugen (besonders wichtig: die Analfalte; hier bleiben oft einzelne Mollusca zurück, von denen ein Rezidiv ausgehen kann). Komplikationen: pyogene Superinfektion.

Histologie. Das histologische Bild ist pathognomonisch: eine epidermale Zyste, innerhalb welcher die Keratinozyten geschwollen und von sog. Molluscumkörperchen erfüllt sind (Feulgen-positive intrazytoplasmatische große Viruspartikel). Diese Einschlußkörperchen treten in mittleren Lagen des Zystenepithels in Erscheinung, reifen bei Wanderung in die höheren Schichten, werden schließlich in das Zystenzentrum abgestoßen und bilden dort den Molluscumbrei.

Therapie. Exprimieren oder Entfernung mit scharfem Löffel. Obwohl es sich im Grunde um eine selbstlimitierte Krankheit handelt (Dauer üblicherweise mehrere Monate), kommt es nicht selten durch wiederholte Autoinokulation zu Rezidiven. Die Übertragung beim Erwachsenen erfolgt häufig durch den Geschlechtsverkehr; Mollusca contagiosa sind daher eine fakultative „sexually transmitted disease“.

\section{Viruswarzen}

Definition. Viruswarzen (im klassischen Sinn) sind durch humane Papillomviren (HPV) erregte Akanthome von benignem, selbstlimitiertem Charakter. In bestimmten Ausnahmefällen kann es jedoch zu maligner Entartung kommen.

Bemerkung: Der Wissensstand um die HPV ist in den letzten Jahren sprungartig angewachsen. Es ist zwar das Dogma aufrecht, daß „klassische“Viruswarzen nur äußerst selten maligne entarten; man weiß aber heute, daß „,high

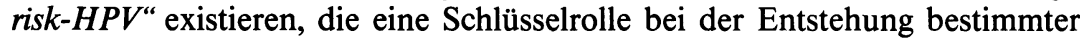
Karzinome spielen (s. unten). Solche high risk-HPV rufen jedoch gewöhnlich nicht (Vorläufer-)Läsionen vom Typ klassischer Viruswarzen hervor.

Erreger. HPV sind Vertreter der Papovavirusgruppe (Erreger tierischer Papillome und maligner epithelialer Tumoren). Sie sind runde DNS-Viren; ihr Kapsid besitzt zwei Strukturproteine, die die gruppen- und typenspezifischen Virusantigene tragen. Ihr Core besteht aus einer ringförmigen doppelsträngigen Virus-DNS mit etwa achttausend Basenpaaren. Alle Typen haben eine ähnliche Genomorganisation und erhebliche Homologien in ausgewählten Abschnitten.

HPV-Systematik. Bis vor kurzem glaubte man, daß nur ein oder sehr wenige HPV-Typen existierten und die Vielfalt klinischer Erscheiungsformen durch 
Tabelle 10. Charakteristische Erreger bei klinischen Warzentypen

\begin{tabular}{|c|c|c|}
\hline Warzentyp & $\begin{array}{l}\text { Haupterreger } \\
\text { HPV-Typ }\end{array}$ & $\begin{array}{l}\text { daneben Erreger der } \\
\text { HPV-Gruppe }\end{array}$ \\
\hline Verrucae plant. (Myrmecien) & 1 & \\
\hline Verrucae plant. (Mosaikwarzen) & 2,4 & \\
\hline Verrucae vulg. & $1,2,4$ & $\mathrm{~B}, \mathrm{~F}, \mathrm{I}$ \\
\hline Fleischhauerwarzen & 7 & \\
\hline Verrucae planae juveniles & 3,10 & $\mathrm{~B}$ \\
\hline Larynxpapillome & 6,11 & \\
\hline Condylomata acuminata & 6,11 & $\mathrm{~A}, \mathrm{~B}, \mathrm{G}, \mathrm{J}$ \\
\hline Condylomata plana & $\begin{array}{l}6,11 \text { (low risk) } \\
16,18,31 \text { (high risk) }\end{array}$ & \\
\hline Bowenoide Papulose & 16 & $\mathrm{~L}, \mathrm{~N}$ \\
\hline Morbus Heck & 13,32 & \\
\hline Epidermodysplasia verruciformis & 5,8 & $\mathrm{D},+$ diverse andere \\
\hline
\end{tabular}

Terrainfaktoren bedingt sei. Es trifft jedoch das Gegenteil zu: Bis jetzt sind mehr als $40 \mathrm{HPV}$-Typen bekannt, die weitgehend mit spezifischen klinischen Bildern korreliert sind (Unterschiede in Morphologie, Prädilektionsstellen, Histologie und biologischer Charakteristik; Tabelle 10). Da HPV nicht in Zellkulturen propagiert werden können, muß die Typendiagnostik aus Gewebematerial erfolgen, und zwar mit der molekularbiologischen Methode der in situ-Hybridisierung (serologische Charakterisierung reicht nicht aus, da Strukturproteine nicht stets und nicht in genügender Menge ausgebildet werden).

Prinzip der In situ-Hybridisierung: Einzelsträngige DNS (bzw. RNS)-Fragmente lagern sich bei hohem Grad von Homologie aneinander und bilden stabile Hybriddoppelstränge aus. Inkubiert man daher die zu untersuchende DNS(RNS) mit (meist radioaktiv) markierter Referenz-DNS(RNS), wird das Gewebe bei Vorliegen von Homologie markiert. Bei der HPV-in-situ-Hybridisierung wird zuerst die doppelsträngige virale DNS in Einzelstränge getrennt und unter geeigneten Bedingungen mit der (gleichfalls einzelsträngigen) Referenz-DNS inkubiert. Das Ausmaß der Reassoziation wird quantitativ ausgewertet; Typenverschiedenheit besteht bei weniger als $50 \%$ Kreuzreaktivität. Die auf diese Weise bisher nachgewiesenen 45 HPV-Typen werden in 16 Gruppen (A-P) zusammengefaßt (Tabelle 11).

HPV-Typen mit besonderen Eigenschaften. HPV-16, HPV-18 und HPV-31 werden als high-risk $H P V$ hervorgehoben; sie kommen vorwiegend in planen Kondylomen vor (siehe unten) und sind an der Entstehung des Zervixkarzinoms und anderer (Genital-)Karzinome beteiligt. Eine zweite Gruppe von HPV-Typen (HPV-5 und eine Reihe anderer - s. Tabelle 10) führt bei Personen mit normaler Immunlage nur zu klinisch stummen Infektionen, im Rahmen der Epidermodysplasia verruciformis oder bei erworbenen Immundefekten jedoch zu sehr extensivem Befall und bei Einwirkung zusätzlicher 
Tabelle 11. Typen und Gruppen humaner Papillomviren (HPV) (Nach Pfister, 1986)

\begin{tabular}{|c|c|c|c|c|c|c|c|c|c|c|c|c|c|c|c|c|}
\hline A & B & C & & D & $\mathrm{E}$ & $\mathrm{F}$ & $\mathrm{G}$ & $\mathbf{H}$ & I & $\mathbf{J}$ & K & $\mathbf{L}$ & $\mathbf{M}$ & $\mathbf{N}$ & $\mathrm{O}$ & $P$ \\
\hline \multirow[t]{11}{*}{1} & 2 & 4 & 5 & 924 & 6 & 7 & 16 & 18 & 26 & 30 & 33 & 34 & 35 & 39 & 41 & 44 \\
\hline & 27 & & 8 & 15 & 11 & & 31 & 32 & & & & & & & & \\
\hline & 29 & & 12 & 17 & 13 & & & 40 & & & & & & & & \\
\hline & 3 & & 14 & 37 & 43 & & & 42 & & & & & & & & \\
\hline & 10 & & 19 & 38 & & & & & & & & & & & & \\
\hline & 28 & & 20 & 45 & & & & & & & & & & & & \\
\hline & & & 21 & & & & & & & & & & & & & \\
\hline & & & 22 & & & & & & & & & & & & & \\
\hline & & & 23 & & & & & & & & & & & & & \\
\hline & & & 25 & & & & & & & & & & & & & \\
\hline & & & 36 & & & & & & & & & & & & & \\
\hline
\end{tabular}

karzinogener Faktoren (UV-Licht!) häufig zu Plattenepithelkarzinomen. HPV-7 schließlich ist wahrscheinlich animalen Ursprungs und ruft fast ausschließlich bei Fleischern sehr hartnäckige Verrucae vulgares der Hände hervor.

Infektionsweg, Biologie der Infektion, Epidemiologie. Viruswarzen sind weltweit verbreitet, gehören zu den häufigsten Virusläsionen und besitzen einen Inzidenzgipfel im 2. Lebensjahrzehnt. Die Infektion erfolgt direkt durch den Kontakt mit einem Warzenträger oder über unbelebte Vektoren. Letzterer Infektionsweg ist durchaus häufig (fast epidemisches Auftreten in Schulklassen; Übertragung wahrscheinlich durch Inokulation virustragender Hornschüppchen vom Boden des Turnsaals, am Schwimmbecken etc.). Bei Schleimhautwarzen erfolgt die Übertragung vorwiegend durch sexuelle Kontakte. Die Viren gelangen durch kleine Verletzungen zu den Basalzellen und infizieren diese. Die Inkubationszeit beträgt mehrere Wochen bis Monate. In Basalzellen können sich die Viren nicht vermehren, die Virusreplikation erfolgt suprabasal. Mit fortschreitender Differenzierung der Keratinozyten schreitet auch die Expression viraler Gene fort, es kommt zur Synthese viraler Strukturproteine und schließlich zur Bildung reifer Viruspartikel (Stratum granulosum, Stratum corneum). Hier kann man virale Einschlußkörperchen bzw. Virus-DNS auch histologisch erkennen (s. unten). Die Virus-DNS liegt in der Regel in Plasmidform vor; lediglich bei high risk-HPV kommt es zur Inkorporation der Virus-DNS in das Wirtsgenom.

HPV-Infektionen sind durch zwei bemerkenswerte Aspekte gekennzeichnet:

- Neigung zur Spontanregression der Viruswarzen: Diese trifft vorwiegend auf die Warzen der Haut zu, kann nach sehr verschieden langer Zeit (Wochen oder Jahre) erfolgen und ist wahrscheinlich, zumindest teilweise, eine immunologische Reaktion (bei den Betroffenen finden sich komplementfixierende Antikörper gegen Virusantigene und eine zellmediierte Immunreaktion). Die Spontanregression kann gelegentlich außerordent- 
lich schnell und an allen bestehenden Warzen gleichzeitig auftreten; dieses Phänomen ist seit altersher bekannt und wird häufig als psychogen induziert interpretiert. Darauf basierend beruht die auch heute noch weitgeübte sog. Suggestivtherapie der Viruswarzen, die im harmlosesten Fall die Pinselung mit auffälligen Farben (etwa Eosin) umfaßt, in bizarreren Fällen das bekannte „Besprechen“ von Warzen etc. Jedenfalls ist das spontane Abfallen von Warzen meist mit einer bleibenden Immunität verknüpft.

Wegen der außerordentlichen Verbreitung des Warzenvirus ist es wahrscheinlich, daß jedes Individuum zumindest einmal eine Minimalinfektion durchgemacht hat; zumeist hat es damit sein Bewenden, die wenigen Läsionen werden durch Änderung der Immunitätslage eliminiert, Rezidive bleiben aus. Bei schlechter Abwehrlage (etwa 10\% der Schulkinder) kommt es zu multiplen Warzen, die über Jahre hinweg einen chronischrezidivierenden Verlauf nehmen können und schließlich gleichfalls spontan abheilen. Bei noch schlechterer Abwehrlage entstehen weit ausgebreitete Infektionen (Volksmund: „Warzenkönig“). Solche Kinder stellen oft eine Crux medici dar, da es nach Behandlung häufig zu Rezidiven kommt, gelegentlich bis weit in das Erwachsenenalter. Den Extremfall in diesem Spektrum stellt die sog. Epidermodysplasia verruciformis (LewandowskyLutz) dar.

- Neigung zu subklinischer Infektion bzw. Viruspersistenz: HPV-Infektion kann klinisch inapparent verlaufen oder nach Spontanremission bzw. erfolgreicher Therapie weiterhin latent bestehen bleiben. Man kann im Umkreis von 1-2 cm einer Viruswarze in der klinisch unbefallenen Haut HPV-DNS nachweisen (Ursachen der hohen Rezidivrate nach Therapie!). Viruspersistenz nach klinischer Ausheilung einer HPV-Infektion ist wahrscheinlich die Regel. Das Ausmaß der latenten Durchseuchung der Bevölkerung mit HPV-Viren ist nicht bekannt aber zweifellos sehr hoch. Hierfür spricht auch das häufige (40\%) Auftreten ausgedehnter Viruswarzen bei Absinken der Immunlage (z. B. nach Nierentransplantation).

Klinische Bilder. Man unterscheidet folgende klinische Manifestationen von Viruswarzen:

\section{- Verrucae vulgares:}

Diese sind der häufigste Typ, kommen vorwiegend an den Dorsalseiten der Finger und der Handrücken vor; hautfarbene, hyperkeratotische halbkugelige oder flache Knoten mit einer charakteristischen papillären rauhen Oberfläche. Gelegentlich finden sich riesenhafte oder auch durch zentrale Regression siegelringartige Warzen. Ursprünglich einzelstehend, können Verrucae vulgares zu größeren plattenartigen Konvoluten konfluieren. Eine besonders unangenehme Variante sind die perionychalen Warzen, die ein therapeutisches Problem darstellen (Gefahr der Verletzung der Nagelmatrix) und auch per se zu Onychodystrophie führen können.

- Verrucae plantares:

Diese können als einzelstehende, endophytische und tiefe Läsionen (Myrmezien) oder oberflächlich und zu Beeten aggregiert auftreten 

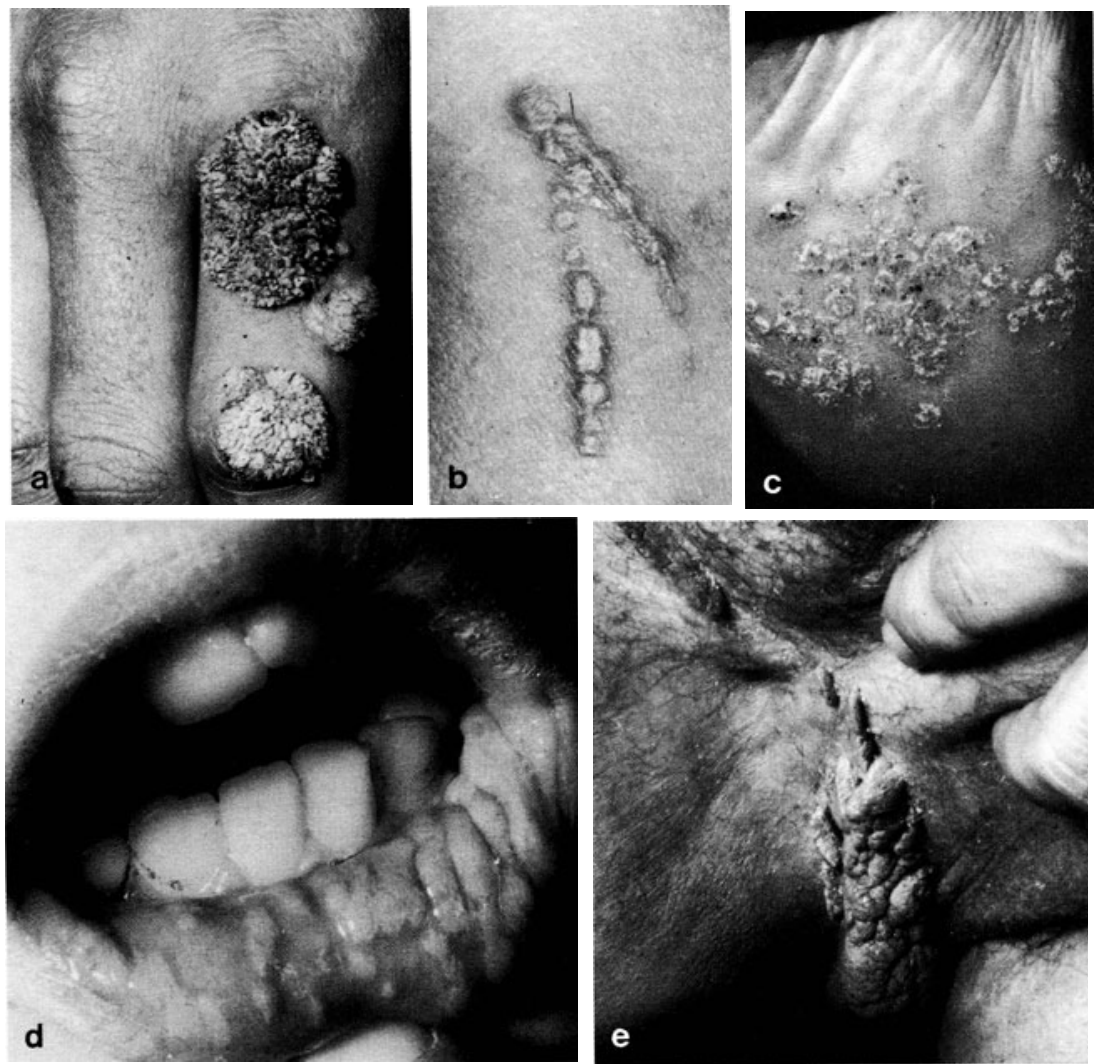

Abb.71a-e. Verschiedene Erscheinungsformen von Viruswarzen: a V.vulgares; b lineare Anordnung von V.planae (Autoinokulation!); c Fußsohlenwarzen (Mosaiktyp); d Mundschleimhautwarzen; e Condylomata acuminata

(Mosaikwarzen). Aufgrund ihrer Lokalisation an den Fußsohlen können Plantarwarzen wegen des beständigen Druckes nicht exophytisch wachsen, werden in die Dermis eingedrückt (schmerzhaft!) und wachsen „umgestülpt“. Plantarwarzen sind zwar als knotige Verdickungen tastbar, man sieht jedoch häufig lediglich einen zentralen Porus (Umstülpungsstelle). Bei Mosaikwarzen finden sich zahlreiche solcher Pori nebeneinander.

- Verrucae planae juveniles:

Diese multiplen, kaum tastbaren, flach erhabenen Läsionen unterscheiden sich von der umgebenden Haut meist durch nichts als eine matte und etwas sattere Farbe (wegen der papillären Oberfläche); sie werden am ehesten mit Epheliden und eruptiven kleinen Verrucae seborrhoicae verwech- 


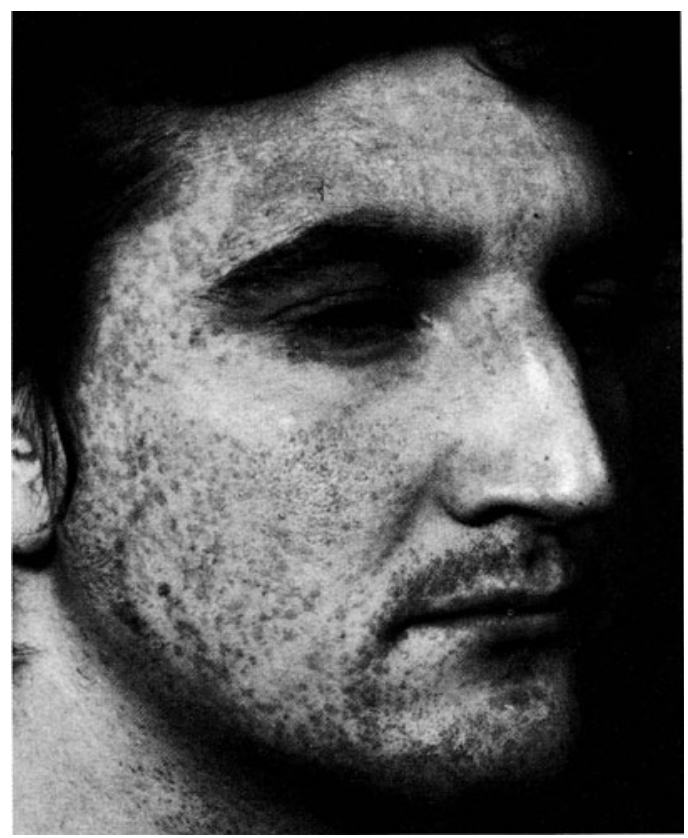

Abb.72. Verrucae planae vom „Pityriasis versicolor-artigen“ Typ bei Epidermodysplasia verruciformis

selt. Verrucae planae treten vorwiegend im Gesicht und an den Handrükken auf, zeigen oft artifizielle Verteilungstypen (etwa strichförmig durch Autoinokulation beim Kratzen) und zeichnen sich durch eruptives Auftreten, aber auch schnelles Ansprechen auf Therapie und schnelle Spontaninvolution aus.

- Filiforme Warzen:

Dünne, zapfenartige verruköse Gebilde hauptsächlich im Gesicht und an der Halsgegend.

- Condylomata acuminata (Feigwarzen):

Diese Erscheinungsform der Viruswarzen ist an feuchte und warme Lokalisationen gebunden: Genitoanalbereich, Intertrigostellen (ausnahmsweise). Es handelt sich um hautfarbene bis rötliche multiple, weiche, warzige Gebilde, die sich relativ schnell vermehren und $\mathrm{zu}$ größeren papillomatösen Knoten oder plattenartigen Vegetationen anwachsen können („Hahnenkamm“- bzw. „Feigen“-ähnlich). Condylomata acuminata werden durch den Geschlechtsverkehr übertragen und können einen hartnäckigen, immer wieder rezidivierenden Verlauf nehmen. Bei starker Ausprägung und mangelnder Reinlichkeit kann es durch Sekretstau zu bakteriellen Superinfektionen und schmerzhaften Entzündungen kommen; eine 
seltene Komplikation ist invasives Wachstum (perforierende Condylomata acuminata) mit Entwicklung von Fisteln. Problematisch sind aufgrund ihrer Lokalisation Condylomata der Fossa navicularis urethrae und solche des Analkanals und des Anoderms. In diesen Fällen ist lediglich operative Therapie erfolgreich (s. unten). Als gefährlichste Verlaufsform gelten die extrem seltenen und destruierend wachsenden sog. „Riesencondylomata acuminata" (Buschke-Löwenstein); es handelt sich hierbei jedoch um den Übergang in ein bzw. schon um das Vorliegen eines wohldifferenzierten Plattenepithelkarzinoms (verruköses Karzinom; s. Seite 469).

Differentialdiagnose. Condylomata lata (breitbasig, bräunliche Farbe; papillärer Aufbau fehlt). Condylomata plana (s. unten).

Hinweis: Falsche Orthographie der Condylomata acuminata ist ebenso verräterisch für mangelnde klassische Bildung wie „der“ Virus oder das „Exzem“. Man schreibt sie mit einem „c“, weil sie sich von „acuminatus“ (spitz) ableiten, hingegen mit Akkumulatoren nichts zu tun haben. In der Nachkriegszeit arbeitete in Wien an einer Hautklinik ein „falscher" Arzt, dem man allerdings bald auf die Schliche kam, weil er immer von „Condylomata acculuminata“ sprach (ein damals weitverbreitetes Übel). Man fragt sich, wie schnell er damit heute auffallen würde.

- Condylomata plana:

Eine bis vor kurzem unbekannte Manifestationsform genitaler HPV-Infektion, die jedoch zumindest ebenso häufig ist wie Condylomata acuminata. Es handelt sich um multiple, unscheinbare, flach erhabene Papeln am

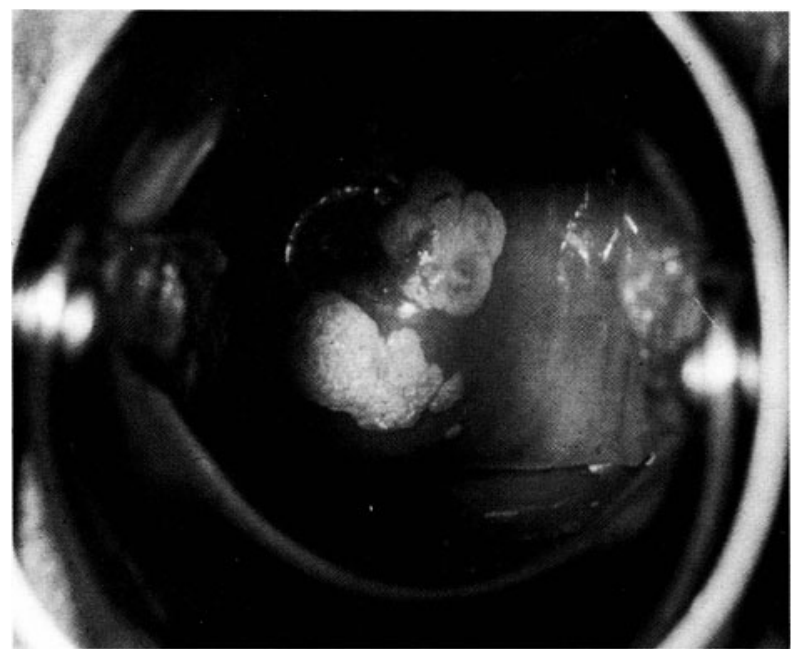

Abb.73. Condylomata plana an der Zervix 
äußeren Genitale beider Geschlechter sowie vor allem intravaginal und an der Zervix. Hier sind sie oft erst durch Kolposkopie erkennbar. Plane Kondylome der Zervix erscheinen im histologischen Bild leicht ,unruhig“ (frühere Bezeichnung: „milde zervikale Dysplasie“), zytologisch sind sie durch sogenannte Koilozyten charakterisiert (Zervikalepithelzellen mit zytopathogenem Effekt durch HPV - große perinukleäre Vakuolen, oft Doppelkernigkeit; Abb.74).

Condylomata plana sind, ebenso wie Condylomata acuminata, eine „sexually transmitted disease“. Die Infektiosität ist relativ hoch (ca. 60\%), die Inkubationszeit beträgt 4-6 Wochen. Als häufigster Erreger finden sich HPV-Typen 6 und 11 (ähnlich wie bei Condylomata acuminta), viel seltener die high-risk-HPV-Typen 16 und 18 (etwa 20\%).

- Merke: Flache Kondylome durch low-risk bzw. high-risk-HPV können klinisch nicht voneinander unterschieden werden; histologisch sind HPV 16 induzierte plane Kondylome jedoch durch Kernatypien in allen Schichten des Epithels, abnorme Mitosen, aber nur wenige Koilozyten charakterisiert (,Zervikale intraepitheliale Neoplasie“, ZIN). Da nur die letzteren als Vorläuferläsion eines Zervixkarzinoms gelten (siehe unten), ist die Typenbestimmung durch in situ-Hybridisierung außerordentlich wichtig. Eine solche Untersuchung als Massenscreening ist von großem gesundheitspolitischem Interesse, wird jedoch bislang erst an wenigen Zentren durchgeführt.

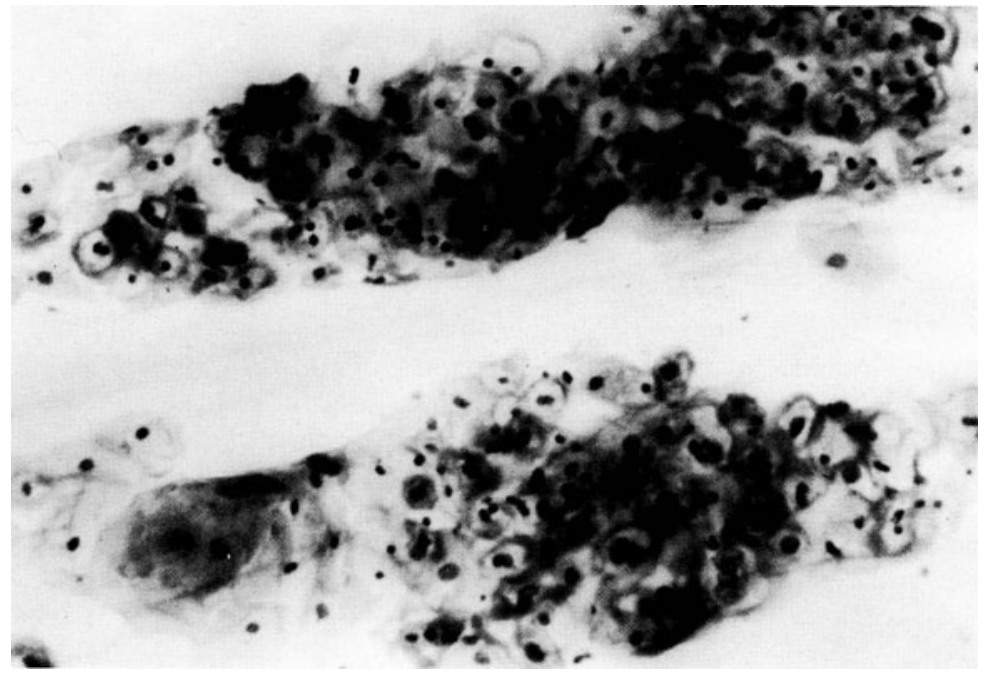

Abb.74. Koilozyten in einem Zervikalabstrich (P. Krause, Univ.-Frauenklinik Innsbruck) 
Sonderform von Condylomata plana (,Bowenoide Papulose“): Es handelt sich hier um multiple flache Kondylome am äußeren Genitale beider Geschlechter (vorwiegend bei Männern), die durch high-risk-HPV erregt sind. Dem unauffälligen klinischen Bild mit entfernter Ähnlichkeit mit Lichen ruber stehen in der Histologie erhebliche Kernatypien und reichlich Mitosen nach Art eines Morbus Bowen gegenüber. Trotz dieses erschreckenden histologischen Bildes sind die Läsionen jedoch sehr chronisch und kommen häufig zu spontaner Regression (allerdings nach Monaten bis Jahren). Trotzdem muß die „bowenoide Papulose“ als Vorläuferläsion genitaler Karzinome des Mannes betrachtet werden, da in letzteren HPV-16 nachgewiesen wurden. Offensichtlich ist die Gefahr einer neoplastischen Transformation von bowenoiden Papeln erheblich geringer als bei flachen Kondylomen der Zervix (wahrscheinlich durch unterschiedliche Wirksamkeit kokarzinogener Faktoren).

- Larynxpapillome:

Larynxpapillome werden fast ausschließlich durch HPV-6 und -11 erregt. Wegen dieser Erregerspezifität und der Prädilektion von Kindern glaubt man, daß die Infektion beim Geburtsvorgang von genitalen Kondylomen her erfolgt (wegen der Seltenheit von Larynxpapillomen jedoch keine Indikation zur Sectio!). Larynxpapillome haben einen zweiten Inzidenzgipfel bei 40-60 Jahren; auch hier wurde HPV-6 nachgewiesen (Reaktivierung eines latenten Infektes?). Die Inzidenz maligner Transformation ist bei letzteren mit $20 \%$ relativ häufig. Juvenile Larynxpapillome entarten fast stets nur nach Röntgenbestrahlung.

- Mundschleimhautwarzen (fokale epitheliale Hyperplasie, Morbus Heck):

Ein Krankheitsbild, dessen HPV-Ätiologie erst in den letzten Jahren erkannt wurde. Morbus Heck ist durch multiple hautfarbene bis weißliche Papeln der gesamten Mundschleimhaut (Lippen, Wangen, Zunge) gekennzeichnet; er tritt gehäuft bei Indianern und Eskimos auf und wurde erst in den letzten Jahren auch bei uns beobachtet.

Differentialdiagnose: Leukoplakien, White Sponge-Naevus.

- Epidermodysplasia verruciformis:

Hierbei handelt es sich um eine exzessive generalisierte, jeglicher Therapie trotzende Verrukose. Sämtliche der genannten Warzentypen können weite Teile des Körpers bedecken; besonders auffällig sind jedoch plane Warzen im Gesicht und am Rumpf (Läsionen von „,seborrhoischem“ bzw. Pityriasis versicolor-ähnlichem Aussehen). Zugrunde liegt ein spezifischer Immundefekt, der familiär gehäuft, jedoch ohne klar definierbaren Vererbungsmodus auftritt. Epidermodysplasia verruciformis wurde früher für eine Genodermatose gehalten; wesentlich ist die außerordentlich häufige maligne Entartung (bis 30\%). Die Plattenepithelkarzinome liegen fast stets an lichtexponierten Arealen und beruhen wahrscheinlich auf einem synkarzinogenetischen Effekt von UV-Licht und Warzenvirus. Patienten mit Epidermodysplasia verruciformis können mehrere (bis zu sechs) verschiedene HPV-Typen tragen, doch persistieren in malignen Tumoren fast ausschließlich HPV-5 und 8 (Plasmidform). 
Eine der Epidermydysplasia ähnliche massive Warzeneruption kann sich gelegentlich unter erworbenen Zuständen der Immundefizienz, etwa unter immunsuppressiver Behandlung, einstellen. Auch hier überwiegt HPV-5.

Maligne Entartung HPV-induzierter Läsionen. Eine Reihe tierischer Papovaviren induziert maligne Tumoren; HPV hielt man früher diesbezüglich für eine Ausnahme. Die Irrigkeit dieser Annahme zeigte sich zuerst am Beispiel der Epidermodysplasia verruciformis. Allerdings ist die karzinogene Potenz verschiedener HPV-Typen sehr unterschiedlich: In den Karzinomen bei Epidermodysplasia verruciformis kann man beispielsweise trotz der Erregervielfalt fast stets nur HPV-Typ-5 und -8 nachweisen, bei den virusinduzierten Karzinomen des Genitaltraktes sind es die oben genannten high risk-HPV. Ist die Epidermodysplasie die Vorläuferläsion mit der höchsten Inzidenz HPV-induzierter Plattenepithelkarzinome, so sind die planen Kondylome die häufigsten und wichtigsten. In mehr als $90 \%$ invasiv wachsender Zervixkarzinome kann high-risk-HPV-DNS nachgewiesen werden; sie entstehen offensichtlich aus planen Kondylomen der Zervix mit dem entsprechenden HPVTyp. Allerdings ist die maligne Transformation solcher high-risk-Kondylome kein frühes Ereignis, da der Inzidenzgipfel von planen Kondylomen und Zervixkarzinomen 20 bis 30 Jahre auseinanderliegen. Auch scheint die Häufigkeit der malignen Transformation nicht besonders hoch zu sein: nur $5-10 \%$ der Befallenen entwickeln innerhalb von 18 Monaten mittelschwere bis schwere zervikale Dysplasien oder sogar Karzinome in situ, während 70\% in dieser Zeit spontan abheilen. High-risk-HPV wurden auch in Vulva-, Penis- und Analkarzinomen gefunden. Solche entstehen offensichtlich gleichfalls aus planen Kondylomen, doch scheint hier die Häufigkeit maligner Transformation noch niedriger zu sein als bei Zervixkarzinomen. Als Grund hierfür vermutet man, daß an der Zervix zusätzliche physikalische, chemische oder infektiöse (Herpes simplex) karzinogene Faktoren wirksam sind. Auch in Larynxkarzinomen und Karzinomen der Mundschleimhaut wurde HPVDNS nachgewiesen.

Bemerkung: Die klinisch inapparante Durchseuchung mit high-risk-HPV in der gesunden Bevölkerung ist noch nicht genau bekannt. Im Rahmen der Krebsvorsorge wurden bei Frauen mit völlig normalen kolposkopischen und zytologischen Cervixbefunden in 10\% HPV-DNS gefunden; ein solcher Befund gibt zwar noch nicht Anlaß zu radikaler Therapie, wohl aber zu regelmäßiger Kontrolle. Fraglos handelt es sich um einen äußerst bedeutsamen Problemkomplex, dem in Zukunft viel Augenmerk geschenkt werden muß.

Histologie. Viruswarzen sind gekennzeichnet durch mächtige Hyperkeratose, charakteristische ausgezipfelte pseudoepithelomatöse Hyperplasie, eine bei manchen Warzentypen recht ausgeprägte Vakuolisierung im Stratum spinosum, sehr typische klumpige Beschaffenheit und Reichlichkeit der Keratohyalinkörner sowie durch eosinophile intranukleäre Einschlußkörperchen in der Höhe des Stratum granulosum. Ein weiterer charakteristischer Befund ist 
die sog. Pseudoparakeratose; kernähnliche Virus-DNS innerhalb der Hornschicht, oft in säulenförmiger Anordnung. Bowenoide Papeln sind durch Akanthose, gestörte Stratifizierung, zahlreiche und atypische Mitosen bei Fehlen der übrigen histologischen Merkmale von Viruswarzen gekennzeichnet.

Therapie. Ein leider häufig verletzter Grundsatz der Therapie ist, daß Viruswarzen der Haut eine benigne, selbstlimitierte Infektion sind und daher nur in besonderen Fällen einer invasiven Therapie unterzogen werden sollten. Grundsätzlich ist zuerst allen konservativen Maßnahmen der Vorzug zu geben (keratolytische Salben, Hauthobeln; dies besonders bei Plantarwarzen, da hierbei durch Verdünnung der Hyperkeratose die eingestülpten spornartigen Plantarwarzen langsam auswärts wandern und dadurch die Schmerzen weitgehend behoben werden). Unter solchen Maßnahmen kommt es häufig zur (induzierten oder vielleicht auch spontanen) Abstoßung der Warzen. Bei Ausbleiben dieses Effektes kann ein wenig aggressiver vorgegangen werden (Excochleation), wobei jedoch nicht selten ein Rezidiv zustande kommt. Ähnliches gilt für die Behandlung mit flüssigem Stickstoff. Die rezidivreichste Methode ist die elektrokaustische Entfernung. Elegant, aber nicht unproblematisch ist die Warzentherapie mit Hilfe der Kontaktsensibilisierung. Hierfür wurde früher Dinitrochlorobenzol (DNCB) verwendet, das jedoch heute wegen möglicher Karzinogenität aus dem therapeutischen Instrumentarium gestrichen wurde. Ein gleich wirksames Nachfolgepräparat wurde bislang noch nicht gefunden. Es wurde eine auf den Applikationsort beschränkte Kontaktdermatitis erzeugt und durch diese die Abstoßung nicht selten auch distanter Viruswarzen herbeigeführt, wofür möglicherweise eine Immunreaktion gegen Warzenvirusantigene verantwortlich war. Die DNCBTherapie eignete sich v. a. für Warzen in Lokalisationen, wo chirurgische Eingriffe zu permanentem Schaden durch die unausbleibliche Narbenbildung führen können (perionychiale Warzen). Weitere chemische Warzenmittel sind 5-Fluorouracil (wirksam, aber etwas aggressiv) und Cantharidin (aggressiv, aber wenig wirksam).

Condylomata acuminata sprechen in fast spezifischer Weise auf Lokalapplikation von Podophyllin (30\%ig in alkoholischer Lösung) an. Podophyllin ist eine zytostatische Substanz mit stark irritierender Wirkung, die daher nur vom Arzt angewendet werden darf. Podophyllinlösung wird auf die Kondylome aufgetragen (wenig!), der Überschuß sorgsam abgetupft und nach einer Stunde vom Patienten mit Wasser (Sitzbad etc.) abgebadet. Innerhalb von 24 Stunden kommt es zu einer (bei planmäßigem Ablauf) leichten entzündlichen Reaktion mit Koagulationsnekrose der Kondylome, die spontan innerhalb einiger Tage abgestoßen werden.

- Merke: Podophyllin darf niemals an 2 aufeinander folgenden Tagen angewendet werden, da die Irritation oft mit einer Verzögerung von $48 \mathrm{~h}$ auftritt! Podophyllin wirkt besonders gut bei den weichen, nicht hyperkeratotischen Kondylomen. Manchmal können Kondylome jedoch bei längerem Bestehen hart und warzig werden; in solchen Fällen kann eine Koagulation mit Tri- 
chloressigsäure versucht werden (äußerst aggressiv, darf nur vom Arzt durchgeführt werden!) oder eine elektrokaustische Abtragung erfolgen. Letztere ist stets nur als letzter Ausweg zu betrachten, da meistens Narben gesetzt werden, die sogar zu Strikturen des Introitus vaginae oder der Urethra führen können. Condylomata acuminata am weiblichen Genitale können die gesamte Vagina bis zur Zervix besiedeln; auch in diesem Fall ist der Versuch mit Podophyllin (besonders vorsichtig!) angezeigt; bei Schwangeren ist dies jedoch kontraindiziert, da es durch Resorption von Podophyllin zu Uteruskontraktionen und dadurch zu einem Abortus kommen kann.

Condylomata plana werden am besten mit dem Laser (Neodym-Yag-Laser) behandelt; dies fällt zum überwiegenden Teil in das Aufgabengebiet der Gynäkologie (intravaginale und Zervix-Kondylome).

Eine möglicherweise revolutionierende Entwicklung scheint sich in Form der Behandlung von Viruswarzen mit Interferonen anzubahnen (derzeit allerdings noch im experimentellen Stadium).

\section{Hautinfektionen durch die Herpesvirusgruppe}

Allgemeines. Die Herpesvirusgruppe umfaßt Herpesvirus hominis, das Varicella-Zoster-Virus (VZ-Virus), das Zytomegalievirus und das Epstein-BarrVirus. Hautinfektionen nehmen einen wichtigen Platz nur bei den beiden erstgenannten Erregertypen ein. In beiden Fällen haben die klinischen Manifestationen starke Gemeinsamkeiten: die weitgehende Identität der Primärreffloreszenz (intraepidermales Bläschen mit Virusriesenzellen) und die Neurotropie des Virus (latente Infektion des Spinalganglions, von der aus Rezidive auftreten können).

\section{Herpes simplex}

Erreger. Herpesvirus hominis, ein obligat menschenpathogenes (kein Tierreservoir!), sphärisches DNS-Virus von etwa $100 \mathrm{~nm}$ Durchmesser. Zwei serologische Untertypen sind bekannt (Typen I und II); simple Regel: Herpesvirus I ruft Infektionen oberhalb der Gürtellinie, Typus II (Herpes genitalis) solche unterhalb derselben hervor. Diese Regel ist allerdings nur eine sehr ungefähre; die Infektion mit einem Typ schützt auch nicht gegen Infektionen mit dem anderen.

Allgemeines. Infektionen mit Herpes-simplex-Viren kommen weltweit vor und sind sehr häufig. Die Durchseuchung der Gesamtbevölkerung ist fast vollständig, zumindest mit Typus I. Der Prozentsatz von Individuen mit gegen Herpesvirus hominis Typ I gerichteten Antikörpern steigt während der Kindheit konstant an und erreicht mit der Pubertät etwa 75\%; bei Herpesvirus hominis Typ II steigt die Kurve, entsprechend der präferentiellen Übertragungsweise, später und langsamer an und erreicht erst im jungen Erwachsenenalter einen Durchseuchungsgrad zwischen 30 und $50 \%$. 
Die Übertragung erfolgt durch direkten Kontakt, meist von einer der chronisch-rezidivierenden Manifestationen, etwa Herpes labialis (Küssen), beim Herpes genitalis vorwiegend, wenn auch nicht ausschließlich, durch den Geschlechtsverkehr. Besonders gefährlich ist die Übertragung beim Geburtsvorgang auf das Neugeborene, die zu einer lebensbedrohlichen Herpessepsis führen kann (Herpes genitalis an einer Gebärenden ist Indikation zum Kaiserschnitt!). Auch transplazentare Übertragung von Herpes simplex kommt vor (selten: konnatale Herpesinfektion).

Die klinischen Erscheinungsbilder des Herpes simplex umfassen ein umfangreiches Spektrum, das jedoch durch den sehr klaren und gesetzmäßigen Ablauf des Verhältnisses zwischen Virus und Wirtsorganismus in wenige Grunderscheinungsformen eingeteilt werden kann. Grundsätzlich kann man zwischen Primärinfektionen, Lokalrezidiven und Reinfektionen unterscheiden. Typischer Ablauf (Abb.75): Beim ersten Kontakt mit dem Herpesvirus kommt es in der überwiegenden Zahl der Fälle zu einer subklinischen Infektion, die $\mathrm{zu}$ einer partiellen Immunität führt und durch verschiedene Klassen von Antikörpern serologisch nachgewiesen werden kann. In einer geringeren Zahl kommt es zu einer dramatisch ablaufenden Erstmanifestation, die meist das Bild einer Gingivostomatitis herpetica (Typ I) oder Vulvovaginitis herpetica (Typ II) annimmt. Natürlich kann die Primärmanifestation auch an der Körperhaut entstehen, verläuft dann aber mit erheblich geringerer Intensität. Im Zuge der primären Manifestation kommt es zur Aszension der Herpesviren über die sensiblen Hautnerven zu den regionären Dorsalganglien; die Viren führen hier zu einer latenten Infektion. Dies stellt entweder den Abschluß der pathogenetischen Kette dar (asymptomatische Keimträger), oder aber es kommt durch Deszension, wieder entlang der Hautnerven, beliebig oft zu rezidivierenden Hautläsionen: es entsteht der (chronisch-)rezidivierende Her-

$\because$ Erstinfektion

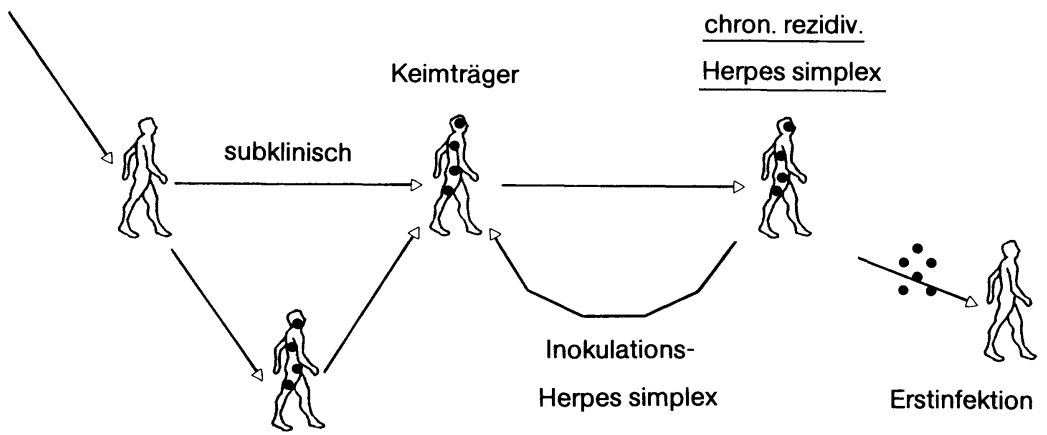

Erstmanifestation

Abb.75. Infektionskette bei Herpes simplex 
pes simplex, der sich zumeist an der Stelle der Primärmanifestation findet und daher typischerweise als Herpes labialis oder Herpes genitalis in Erscheinung tritt.

Die Rezidive werden häufig durch exogene Ursachen (passagere Senkung der Abwehrlage) getriggert: Herpes menstrualis, „Fieberblasen“, Triggerung durch UV-Licht (,Gletscherblasen“). Solche rezidivierenden Herpesläsionen laufen manchmal heftig, in der Regel jedoch eher milde ab und beschränken sich häufig auf klinisch symptomlose Freisetzung von Herpesviren aus der Mund- oder Genitalschleimhaut (Speichel bzw. Genitalsekrete dann infektiös!); solche nahezu symptomlosen Rezidive stellen die Hauptansteckungsquelle dar. Reinfektionen (,Inokulations-Herpes-simplex“) sind jederzeit möglich, da vorhandene Antikörper keine völlige Immunität bewirken.

\section{Klinisches Bild}

- Primäre herpetische Gingivostomatitis (alter Name: „Stomatitis aphthosa“): Nach einer Inkubationszeit zwischen 3 und 10 Tagen auftretende, meist die gesamte Mundschleimhaut und den Pharynx umfassende, diffuse Rötung mit sehr zahlreichen, außerordentlich schmerzhaften Bläschen, begleitender Lymphadenitis und häufig hohem Fieber. Nahrungsaufnahme sehr schmerzhaft, Foetor ex ore, Sialorrhö. Nach einigen Tagen Umwandlung der Bläschen in schmierig belegte, konfluierende, ausgedehnte, oberflächliche Erosionen. Die Abheilung erfolgt spontan nach zumindest 2 Wochen. Prädilektion des Kleinkindesalters.

Differentialdiagnose. Streptokokkenpharyngitis, Plaut-Vincent-Angina, Herpangina, Stevens-Johnson-Syndrom.

Diagnose. Tzanck-Test aus Bläschengrund (Virusriesenzellen!), Negativestain-Präparat (s. unten).

- Primäre herpetische Vulvovaginitis: Bild wie oben transponiert auf den weiblichen Genitaltrakt. Befallen sind hier hauptsächlich junge Mädchen und Frauen; diffuse Schwellung des gesamten äußeren Genitales mit reichlich Herpesbläschen, die sich auch intravaginal, in die Urethra und Harnblase fortsetzen können. Dementsprechend die Beschwerden: Dysurie, manchmal Hämaturie, Harnretention. Hohes Fieber, regionäre Lymphadenopathie, manchmal Meningismus.

Differentialdiagnose. Kontaktdermatitis der Vulva, Lues II, Vaccinia inoculata, schwere Candidiasis.

- Primäre herpetische Genitalinfektion beim Mann: Wie oben, jedoch seltener und weniger intensiv.

- (Chronisch-) rezidivierender Herpes simplex:

Allgemeines. Die häufigste Manifestation des Herpes simplex; allerdings schwankt die Rezidivhäufigkeit außerordentlich (von nur einigen Episoden im ganzen Leben bis zu mehreren Attacken im Monat); grundsätzlich handelt es sich wahrscheinlich um einen - wenn auch oft viele Jahre andauern- 
den - selbstlimitierten Zustand. Ähnlich verschiedenartig ist die Ausprägung der Symptomatik, die von einer kaum merkbaren, juckendbrennenden Sensation bis zu ausgedehnten multiplen Herden mit Systembeschwerden reichen kann.

Klinisches Bild. Im typischen Fall handelt es sich um einen bis münzgroßen, erythematösen, aus gruppierten Bläschen von wasserklarem Inhalt bestehenden Herd; im Laufe einiger Tage kommt es zur Vereiterung und dann Eintrocknung der Bläschen, Verkrustung, Rückgang der entzündlichen Veränderungen und Abheilen (bei schweren Fällen mit atrophen Narben). Die Beschwerden bestehen aus anfangs juckenden, später brennenden Schmerzen; häufig eine begleitende, manchmal ebenfalls schmerzhafte Lymphadenitis. Prädilektionsstellen: Lippen, Gesicht (Typ I), Genitale, Sakralgegend (Typ II).

Obwohl bei der Primärmanifestation die Mundschleimhaut besonders massiv befallen ist, treten chronisch-rezidivierende Herpesläsionen nur sehr selten auf dieser auf; aphthöse Veränderungen der Mundschleimhaut sind in der überwiegenden Mehrzahl der Fälle nicht herpetisch (sondern chronisch-rezidivierende Aphthen oder Erythema multiforme)!

Differentialdiagnose. Sämtliche herpetischen Läsionen anderer Natur, v.a. abortive Fälle von Herpes zoster. Unterscheidungsmerkmal: in einem Zosterherd sind sämtliche Bläschen gruppenweise im gleichen Entwicklungsstadium, bei Herpes simplex herrscht ein gemischtes Bild vor.

- Merke: Chronisch-rezidivierender Herpes simplex ist der häufigste und wichtigste Trigger des Erythema exsudativum multiforme!

- Inokulations-Herpes-simplex (Abb.76): Klinisch vom oben beschriebenen Bild nicht unterscheidbar; tritt bei partiell immunen Patienten nach Inokulation auf (Kontinuitätsdefekte der Haut, z. B. Biß!).

- Eczema herpeticatum: Massive Herpes-simplex-Superinfektion einer Neurodermitis (selten eines anderen ausgedehnten Ekzemtyps); ein hoch fieberhaftes, schweres Krankheitsbild, das meist einer Primärmanifestation der Herpes-simplex-Infektion entspricht (Reinfektionen in Form eines Eczema herpeticatum kommen vor, verlaufen aber milder). Ursache: Infektionsbegünstigung durch den Vorschaden der Haut, v. a. aber durch die mit Neurodermitis verbundene Abwehrschwäche gegen Infektionen. Komplikationen:Herpes-simplex-Enzephalitis.

Klinisches Bild. Auf der neurodermitischen, heftig entzündeten Haut finden sich multiple, disseminierte, häufig zu großen Beeten konfluierende Herpesbläschen, die nach einigen Stunden bis Tagen platzen und zu multiplen, kleinen, runden, wie ausgepunzt aussehenden Erosionen führen (nahezu diagnostisches Bild!). Das Eczema herpeticatum kommt nach ein- bis mehrwöchigem Verlauf spontan zur Abheilung. 


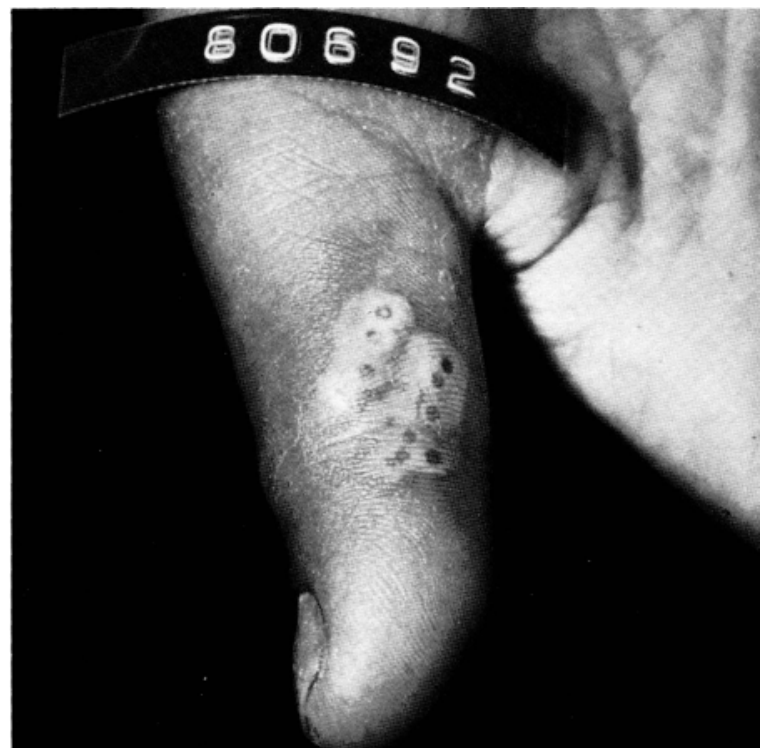

Abb. 76. Herpes simplex. Typische Erscheinung eines Inokulations-Herpes-simplex, wie er etwa bei Zahnärzten, Krankenschwestern und Ringkämpfern vorkommt (Biß in den Finger)

Differentialdiagnose. Eczema vaccinatum, Impetiginisation.

- Merke: Wegen der Gefahr des Eczema herpeticatum dürfen Pflegepersonen mit floridem Herpes simplex keine Manipulationen an Patienten mit Neurodermitis, anderen ausgedehnten Hautveränderungen oder Immunschwäche durchführen. Dies gilt allerdings nur, solange floride Herpesläsionen vorhanden sind; im Intervall sind solche Personen nicht infektiös (Schwierigkeit: minimale Herpesepisoden können unbemerkt verlaufen!).

- Generalisierter Herpes simplex der Neugeborenen: Wegen der physiologischen Abwehrschwäche des Neugeborenen besonders bedenklich. Beim Durchtritt durch den Geburtskanal der Mutter erworben. Disseminierte, generalisierte Herpesläsionen (Bläschen oder „ausgepunzte“ Erosionen), schwere Systemzeichen, schnelle Ausbreitung an die inneren Organe, insbesondere ZNS. Hohe Mortalität!

- Herpes simplex vegetans (Abb.77): Eine sehr wichtige Variante des Herpes simplex von zunehmender Häufigkeit; er tritt bei immundefizienten Patienten auf und ist durch eine langsame, aber schrankenlose periphere Ausbreitung, tiefe eitrige, schmerzhafte Nekrosen und die Gefahr hämatogener Dissemination in innere Organe, insbesondere wieder das ZNS, gekennzeichnet. Beson- 


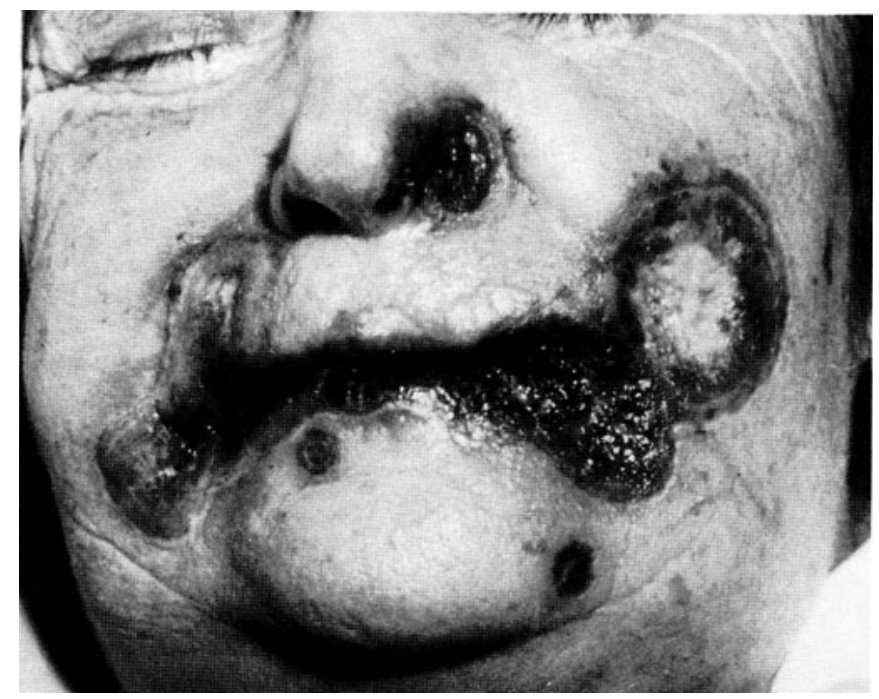

Abb.77. Herpes simplex vegetans. Unaufhaltsam progrediente nekrotisierende Läsionen, von einem chronisch rezidivierenden Herpes simplex ausgehend. Die abgebildete Patientin befand sich in einem präterminalen Stadium einer chronisch-lymphatischen Leukämie. Fast die gesamte Mundschleimhaut war von analogen nekrotisierenden Veränderungen bedeckt

ders gefährdet sind Patienten mit Lymphomen (Leukämien) und Patienten unter Behandlung mit Immunsuppressiva (Organtransplantationpatienten, bei Autoaggressionskrankheiten). Beginnt gewöhnlich mit einer vorerst unauffälligen Episode eines chronisch-rezidiverenden Herpes simplex.Typische Lokalisation: Lippen, Gesicht. Komplikation: Herpes-simplex-Sepsis mit Befall innerer Organe (Herpes-simplex-Enzephalitis!).

Diagnostik. Histologisch ist ein Herpes-simplex-Bläschen durch Spongiose, ballonierende Degeneration der Epidermis und sog. Virusakantholyse gekennzeichnet; charakteristisch sind die Virusriesenzellen (akantholytische Epidermalzellen mit riesigen, meist mehreren Zellkernen). Virusriesenzellen können auch mit Hilfe der exfoliativen Zytologie (Tzanck-Test) im Blaseninhalt nachgewiesen werden (Schnelltest). Der Virusnachweis kann durch eine elektronenmikroskopische Schnellmethode („negative stain“) aus dem Bläscheninhalt geführt werden (Kohlebedampfung: die Viren erscheinen als helle sphärische Partikel über dem elektronendichten Hintergrund; Abb.78). Allerdings sind die Befunde von Histologie, „negative stain“ und Tzanck-Test nicht spezifisch für Herpes simplex, da sich völlig analoge Veränderungen auch bei Varizellen und Herpes zoster finden. Eine Differenzierung kann durch den spezifischen Immunfluoreszenznachweis der Herpesviren am Ausstrichpräparat sowie durch Kultur und serologische Diagnostik erfolgen. 

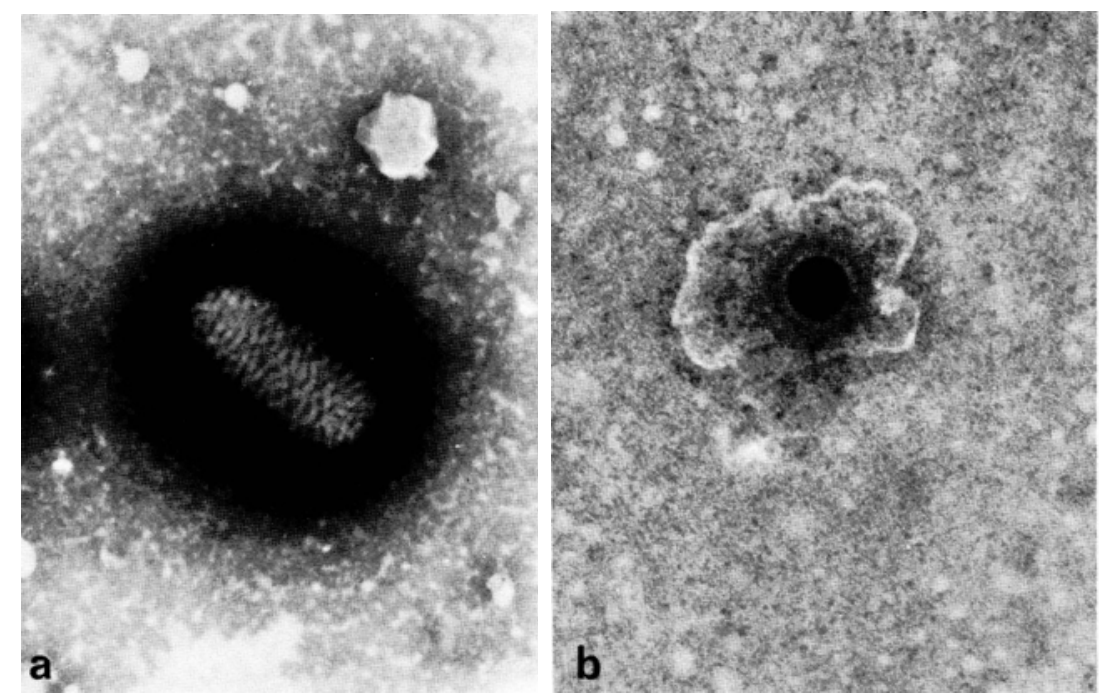

Abb. 78a, b. Negative-stain-Diagnose virusbedingter Läsionen. a Paravacciniavirus aus einem Melkerknoten. b Herpes-simplex-Virus. Vergr. 100000:1

Therapie des Herpes simplex. Primäre herpetische Infektionen werden bei mildem Verlauf mit symptomatischen Mitteln (Mundspülungen bzw. Sitzbäder, entzündungshemmende Mittel, Analgetika etc.) behandelt; Applikation von Lokalanästhetikalösungen kann indiziert sein (sind allerdings kontaktsensibilisierend). Bei schwerem Verlauf wird Acyclovir p.o. oder als Infusionsserie verabreicht (s. Therapeutische Tabellen).

Die Therapie des chronisch-rezidivierenden Herpes simplex ist, in ausgeprägten Fällen, eine Crux medici. Von großer Wichtigkeit ist die korrekte Lokaltherapie: eine schnelle Linderung und manchmal auch Abortion des Prozesses bringt das Öffnen der Bläschen und ihre Austrocknung, sowie Lokalapplikation von Kortikosteroidtinkturen (entzündungshemmender Effekt). Acyclovirsalben sind nur bei sehr frühzeitiger Applikation wirksam.

- Merke: Kortikosteroidpräparationen sind zwar bei Herpes corneae kontraindiziert, da sie zur Perforation der Hornhaut führen können. Bei Herpes-simplex-Läsionen der Haut wirken sie hingegen mildernd; negative Folgen wie beispielsweise lokale Ausbreitung oder hämatogene Dissemination werden nicht beobachtet!

Die Therapie des vegetierenden Herpes simplex galt bis vor kurzem als hoffnungslos; seit Einführung des systemischen Virustatikum Acyclovir können derartige Infektionen - wie auch die meist infauste Herpes-simplex-Enzephalitis - beherrscht werden. Hier ist allerdings oft eine längerfristige Medikation erforderlich. 


\section{Varizellen und Herpes zoster}

Erreger. Varicella-Zoster-Virus (VZ-Virus); ein dem Herpes simplex-Virus ähnliches DNS-Virus. Es ist lediglich humanpathogen und kann auch nur in Primatenzellkulturen gezüchtet werden; es existiert nur ein Serotyp.

Allgemeines. Varizellen und Herpes zoster sind weltweit verbreitet, die Durchseuchung der meisten Populationen ist knapp 100\%. Ähnlich wie bei Herpes simplex bestehen strenge gesetzmäßige Abläufe im Verhältnis von Virus und Wirtsorganismus (Abb.79). Die Primärinfektion (Varizellen) verläuft als fieberhafte exanthematische Erkrankung mit Virämie; die Viren bringen in der Haut die typischen Läsionen zur Ausbildung und aszendieren von dort über die sensiblen Hautnerven zu den regionären Spinalganglien, die sie (ähnlich dem Herpes simplex) lebenslang besiedeln. Bei guter Abwehrlage des Organismus bleibt die Infektion jedoch latent. Sinkt sie unter einen gewissen Schwellenwert ab, kommt es (oft Jahrzehnte nach der Primärinfektion!) zur Virusreplikation, die zuerst eine akute Ganglionitis und anschließend, nach Deszension der Viren in die Haut wieder entlang der sensiblen Hautnerven, einen Herpes zoster im betroffenen Segment hervorruft.

\section{Erstmanifestation: Varizellen}

Definition. Exanthematische, vesikulöse Infektionskrankheit durch das VZVirus im Rahmen der Erstinfektion.

Allgemeines. Betrifft überwiegend Kinder unter 10 Jahren; Infektionen beim Erwachsenen verlaufen meist schwerer. Die Ansteckung erfolgt von an Varizellen oder an Zoster Erkrankten durch Tröpfchen- und Schmierinfektion. Die Kontagiosität bei Varizellen ist sehr hoch (etwa $90 \%$ der nichtimmunen Population), ist jedoch auf die kurze floride Phase (wenige Tage) beschränkt;

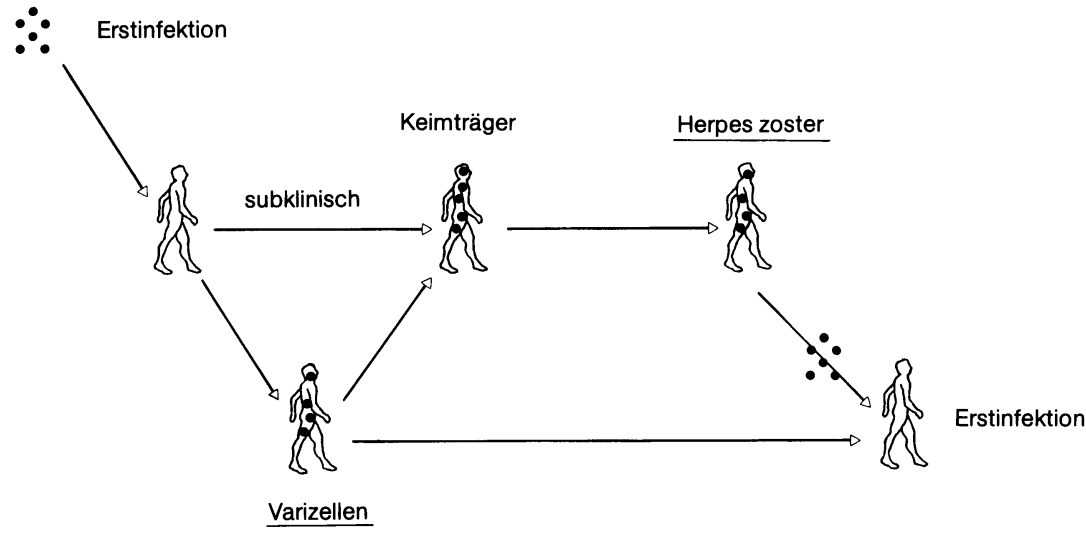

Abb. 79. Infektionskette bei Varizellen-Herpes zoster 
eingetrocknete Varizelleneffloreszenen sind (im Gegensatz zu Pocken!) nicht infektiös. Varizellen verlaufen meist in Form von Epidemien mit typischer saisonaler Häufung im Frühsommer. Varizellen hinterlassen lebenslange Immunität gegen Varizellen (nicht gegen Zoster!).

Klinisches Bild. Die Inkubationszeit ist ca. 2 Wochen; an deren Ende treten Prodrome auf (nicht sehr hohes Fieber, Kopfschmerzen etc.), bei älteren Kindern und Erwachsenen stärker ausgeprägt! Anschließend entsteht ein sich in schnell aufeinander folgenden Schüben entwickelndes Exanthem aus regellos disseminierten, einzelnstehenden Primärläsionen; die Primärläsion ist ein unscharf und unregelmäßig begrenztes kleines Erythem, in dessen Zentrum ein kleines, wasserklares Bläschen sitzt (treffender Vergleich: „Tautropfen auf Rosenblatt").

- Merke: Die Varizellenprimärläsion ist das Musterbeispiel einer sog. Haloläsion.

Die Zahl der Läsionen schwankt zwischen 20 und vielen Hunderten („Sternenhimmel"). Prädilektionsstellen: Kopf und Rumpf, besonders charakteristisch: Kapillitium und Mundschleimhaut. Der Entwicklungsgang der Einzelläsion ist sehr schnell (sämtliche Entwicklungsstadien kommen daher nebeneinander vor); das Bläschen beginnt zentral einzusinken (und erscheint dadurch manchmal ein wenig genabelt) und trocknet schließlich zu einer Kruste ein. Abstoßung der Kruste und Abheilung (narbenlos) erfolgen zwischen 1 und 3 Wochen; in Ausnahmefällen entstehen multiple, runde, atrophe, scharf begrenzte Närbchen. Allgemeinsymptome (Fieber, Abgeschlagenheit, etc.) bestehen nur während der floriden Phase (etwa 3 Tage).

Komplikationen. Neben bakteriellen Superinfektionen (Impetiginisation, in seltenen Fällen Erysipel und Phlegmone) ist es v.a. die gefährliche Varizellenpneumonie, deren Häufigkeit und Intensität mit dem Lebensalter korreliert ist (etwa $10 \%$ Mortalität bei vorher gesunden Erwachsenen!). Seltener ist ZNS-Befall (Meningoenzephalitis, zerebellare Ataxie etc.).

Differentialdiagnose. Das klinische Bild der Varizellen ist kaum verwechselbar; ähnlich sehen können bei mildem Verlauf der sog. Lichen urticatus (s. S. 110) und bei schwerem Zustandsbild die Pocken.

\section{Zweitmanifestation: Herpes zoster}

Definition. Herpes zoster ist eine durch Reaktivation einer latenten Infektion des Spinalganglions entstandene segmentale, vesikulöse Eruption durch das VZ-Virus.

Allgemeines. Die Inzidenz des Herpes zoster nimmt etwa linear mit dem Alter zu, wobei die frühesten Fälle schon innerhalb der ersten Lebensjahre beobachtet werden können. Herpes zoster tritt nicht epidemisch, sondern sporadisch auf. Entgegen weitverbreiteter Meinung wird Herpes zoster nicht durch Kontakt mit an Varizellen oder Herpes zoster Erkrankten akquiriert. 
Pathogenese. Entsprechend der gegenwärtigen Anschauung kommt es nach einer abgelaufenen Varizelleninfektion zur latenten Infektion aller oder der meisten Spinalganglien durch das VZ-Virus (s. oben). Bei Absinken der Immunitätslage ist der Organismus nicht mehr in der Lage, die Virusvermehrung zu unterbinden, es resultiert eine akute Ganglionitis und Ausbreitung der Infektion auf das entsprechende Nervensegment. Dadurch kommt es wieder zur Boosterung der Immunabwehr, so daß die Reaktivierung auf ein einziges, selten auf einige wenige Segmente beschränkt bleibt. Für die Entwicklung der Reaktivierung gerade in einem bestimmten Segment sind die Zahl der latenten VZ-Viren in den Ganglien und lokale Faktoren (Irritation eines Segments durch arthrotische Schäden, Metastasen etc.) verantwortlich. Das Absinken der Abwehrlage ist entweder Folge der natürlichen altersbedingten Abnahme der Immunabwehr oder von Infekten und, vor allem, neoplastischen Krankheiten. Insbesondere bei Lymphomen ist die Häufigkeit und auch der Schweregrad von Herpes zoster sehr hoch (klassische Korrelation!).

Klinisches Bild (Abb. 80). Beginn mit heftigen, einseitigen, auf ein Segment beschränkten neuralgiformen Schmerzen, gelegentlich mit Fieber und milden

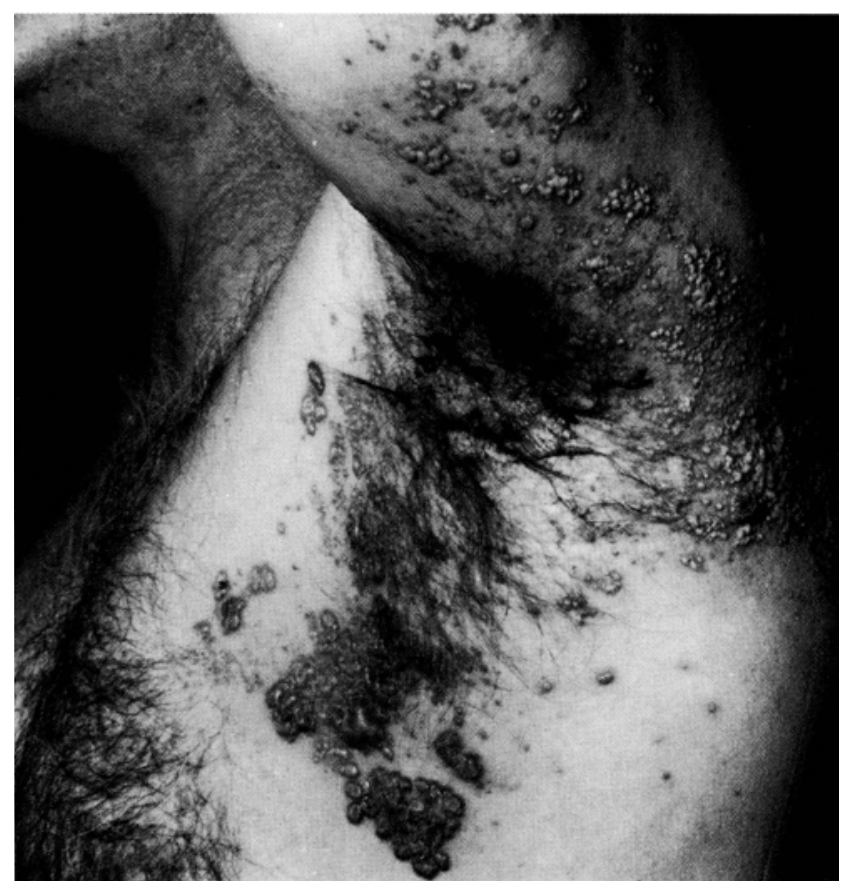

Abb.80. Herpes zoster (Th2): gruppenweise Anordnung der Einzelläsionen, verschiedene Entwicklungsstadien der einzelnen Läsionsgruppen. 
Allgemeinsymptomen. Der Schmerz wird häufig in innere Organe projiziert (Zahnweh, Gallen- und Nierenkoliken, akute Appendizitis etc.); in dieser präeruptiven Periode sind daher voreilig durchgeführte diagnostische oder therapeutische Eingriffe (Appendektomie, Zahnextraktion etc.) nicht selten. Nach einigen Tagen kommt es zum Auftreten mehrerer erythematöser entzündlicher Herde mit gruppierten klaren Bläschen im betreffenden Hautsegment; durch sukzessive Schübe ist dieses schließlich großteils oder gänzlich gürtelförmig, streng halbseitig befallen. An der Medianlinie kommen manchmal kleine Grenzüberschreitungen vor (überlappende Nervenversorgung). Typischerweise erscheinen die dem Spinalganglion näher gelegenen Herde (dorsal) früher (kürzerer Weg!) als die entfernteren (ventral). Die Bläschen innerhalb einer Gruppe sind gleich alt und daher monomorph; Bläschengruppen sind untereinander verschieden alt und daher von verschiedener Morphologie.

Gewöhnlich ist nur ein Segment befallen, in Ausnahmefällen zwei oder mehrere (dann meist benachbart). Sehr selten ist der Befall zweier voneinander entfernter Segmente (Zoster duplex) oder bilateraler Befall (Zoster bilateralis). Prädilektionsstellen: Rumpf und Gesicht.

Entwicklungsgang der Primärefloreszenzen. Das Zosterbläschen unterscheidet sich vom Varizellenbläschen nur durch eine heftigere entzündliche Reaktion und stärkere Tendenz zur Nekrose. Im Durchschnittsfall tritt nach etwa 2 Wochen Abstoßung der Krusten und Abheilung ein. Bei komplizierteren Fällen kommt es zur Nekrose der Einzelbläschen, im Extremfall des gesamten herpetiformen Herdes (Zoster gangraenosus). Die Nekrosen sind häufig hämorrhagisch (Zoster haemorrhagicus).

Mitbeteiligung innerer Organe. Der Befall innerer Organe, entsprechend dem Hautsegment, ist häufig, verläuft aber meist subklinisch. Gelegentlich jedoch kommt es zu einer hämorrhagischen Zystitis, umschriebenen Entzündungen des Gastrointestinaltrakts, Ösophagitis etc. Besonders schwerwiegende Organbeteiligung findet sich jedoch beim Herpes zoster im Bereiche des 1. Trigeminusastes; hier kann es bei Befall des N.nasociliaris zur Augenbeteiligung kommen (Konjunktivitis, Keratitis, Iritis mit Sekundärglaukom etc.).

- Merke: Bei Augenbeteiligung finden sich stets auch Hautläsionen der Nase (diese häufig vorausgehend)!

Ähnlich schwerwiegend ist das Ramsay-Hunt-Syndrom (Befall des N.facialis und statoacusticus): periphere Fazialisparese, Schwindel und Hörverlust (mögliche Folge: Taubheit). Dermatologisches Zeichen des Ramsay-HuntSyndroms: Zosterläsionen im äußeren Gehörgang. Durch lokale Ausbreitung der VZ-Viren in das Vorderhorn kann es manchmal auch zu motorischen Ausfällen kommen (etwa 5\%).

Verlauf. Unkomplizierte Fälle heilen nach 2-3 Wochen unter Zurücklassung depigmentierter, leicht atropher Narben und einer passageren Sensibilitätsstörung ab. Das Auftreten von Komplikationen ist mit dem Alter des Patien- 
ten und seiner Abwehrlage korreliert: bei alten und immundefizienten Personen ergibt sich häufig ein schwerer Verlauf, der sich einerseits in nekrotisierenden Läsionen und andererseits durch Generalisation kennzeichnet. Unter letzterer versteht man das exanthematische Auftreten von Zosterreffloreszenzen (varizellenähnliches Bild). Generalisation ist der klinische Ausdruck hämatogener Dissimenination und bedeutet die Gefahr eines sepsisähnlichen Zustandsbildes mit Befall innerer Organe, in erster Linie der Lunge (Zosterpneumonie) und des ZNS (Zosterenzephalitis). Beide Zustände stellen ernste Komplikationen mit hoher Mortalität dar.

Eine zwar nicht gefährliche, aber äußerst quälende Komplikation ist die postzosterische Neuralgie: wahrscheinlich durch narbige, postinflammatorische Fibrosierung des Spinalganglions bedingt, geht sie entweder kontinuierlich aus den Zosterschmerzen hervor oder entsteht erst einige Wochen nach Abheilung der Hauterscheinungen. Es handelt sich um attackenartige, oft schwerste Schmerzzustände, die besonders durch Kälte und Zugluft getriggert werden können. Zosterneuralgien treten fast stets im Trigeminusbereich auf und sind in ihrer Inzidenz deutlich altersabhängig (Kinder leiden so gut wie nie an Zosterneuralgie, bei Individuen über 70 Jahre ist sie jedoch die Regel). Sie hält im Durchschnittsfall einige Monate an, die Attacken werden dann seltener und sistieren gewöhnlich innerhalb eines Jahres. Selten setzt sich die Zosterneuralgie unbegrenzt fort; in solchen Fällen wird gelegentlich als Verzweiflungsakt eine chirurgische Durchtrennung der Nervenbahnen durchgeführt.

Diagnostik. Wie bei Herpes simplex Tzanck-Test und Negative-stain-Präparat (beweisend). Serologische Tests sind gewöhnlich nicht erforderlich.

Therapie. Der unkomplizierte Zoster wird lediglich mit Lokalmaßnahmen behandelt (vesikulöse Phase: Puder-Watte-Verbände, krustöse Phase: indifferente Fettsalbenverbände zwecks Abkrustung). Gegen mittelgradige Zosterschmerzen werden Vitamin B, Analgetika und Antirheumatika gegeben. Ältere Personen (über 50 Jahre), die mit hoher Wahrscheinlichkeit einer Zosterneuralgie entgegengehen, werden - sofern keine interne Kontraindikation vorliegt - mit einem mittelhoch dosierten ( $40 \mathrm{mg}$ Prednisolonäquivalent) und über etwa 1 Monat durchgeführten Kortikoidstoß behandelt; unter dieser Therapie kommt es zu einer deutlichen Senkung der Inzidenz der Zosterneuralgien und zu einem milderen und kürzeren Verlauf. Kontraindiziert ist eine solche Kortikosteroidtherapie jedoch in Fällen mit Zeichen schlechter Abwehr: nekrotisierender und generalisierter Herpes zoster, Lymphome. Bei schweren Verlaufsformen: Acyclovir per infusionem. Da das VZ-Virus weniger empfindlich gegen Acyclovir ist als das Herpes-simpex-Virus, ist eine perorale Therapie häufig nicht ausreichend (wirksame Blutspiegel werden nicht erreicht).

Merke: Das Auftreten schwerer Zosterformen ist gelegentlich mit noch unentdeckten internen Neoplasien korreliert; eine Tumorsuche ist daher angezeigt. 


\section{Infektiöse Mononukleose}

Erreger. Epstein-Barr-Virus, ein lymphotropes Herpesvirus.

Allgemeines. EBV-Infektionen sind weltweit verbreitet; sie umfassen ein Spektrum, das von asymptomatischer Infektion (im Kindesalter die Regel) bis zu schwersten, potentiell tödlichen Zustandsbildern (Milzruptur, Enzephalitis etc.) reicht. Unter infektiöser Mononukleose versteht man das klinische Krankheitsbild der Erstinfektion, meist bei jungen Erwachsenen (bei diesen verläuft die Infektion schwerer und viel seltener subklinisch). Die Übertragung des (nicht sehr kontagiösen) EBV erfolgt zumeist durch den virushaltigen Speichel (Küssen). Auch Übertragung durch Bluttransfusionen wurde beschrieben. Nach durchgemachter Infektion wird der Erkrankte Virusträger und durch periodisches Virusshedding mit dem Speichel zur Infektionsquelle.

Merke: Zusätzlich zu den genannten Krankheitsbildern ist das EBV auch mit dem hochmalignen Burkitt-Lymphom assoziiert.

Klinisches Bild. Nach einer Inkubationszeit von 30 bis 50 Tagen (bei Kindern kürzer) und Prodromi (Kopfweh, Krankheitsgefühl) Krankheitsbeginn mit Fieber (bis 39 Grad) und akuter Pharyngotonsillitis, Uvulaödem und Petechien am Gaumen. Allmählich entwickelt sich innerhalb der ersten Wochen eine vorerst zervikale Lymphknotenvergrößerung (groß, weich, nicht verbakken, schmerzhaft), die bald die übrigen Lymphknotenstationen des KopfHals-Gebietes erfaßt und schließlich generalisiert. Akute Erscheinungen und Lymphknotenschwellung sind im Regelfall nach 2-3 Wochen abgeklungen, können in manchen Fällen jedoch erheblich länger persistieren und durch Komplikationen verschärft werden. Diese sind vorwiegend neurologischer (Meningoenzephalitis, Myelitis, Neuritis, akutes zerebellares Syndrom, akuter psychotischer Reaktionstyp, Guillain-Barré-Syndrom) oder hämatologischer Natur (hämolytische Anämie, Thrombozytopenie). Häufiges Begleitsymptom ist Splenomegalie (50\%, Cave: Milzruptur!), eher selten $(10 \%)$ Hepatomegalie. Hautsymptomatik: In etwa 10\% der Fälle tritt am Stamm ein eher uncharakteristisches rubeolenähnliches Exanthem auf, das bei besonders schwerem Verlauf hämorrhagisch oder vesikulös sein kann. Charakteristisches Zeichen: Supraorbitales Ödem.

Labor. Absolute Lymphozytose und Monozytose mit atypischen Lymphozyten, Transaminasenerhöhung (oft wochenlang nachhinkend), sogenannter heterophiler Antikörper (Agglutinine gegen Schaferythrozyten - ein noch immer wertvoller Suchtest), spezifische serologische Tests.

Differentialdiagnose. Pharyngotonsillitis: Streptokokkenangina, Diphtherie, Plaut-Vincent'sche Angina, andere virale Anginen. Exantheme: Rubeolen (Unterschied: hier auch Gesicht befallen) und andere Virusexantheme. Lymphadenopathie: Zytomegalie-Virusinfektion, Toxoplasmose. Laborwerte: Hepatitis-B, akute Leukämie. 
Therapie. Konservativ; Acyclovir nur schwach wirksam.

Merke: Verabreichung von Ampicillin im Rahmen einer klinischen oder subklinischen EBV-Infektion führt fast stets zur Ausbildung eines AmpicillinExanthems.

\section{AIDS (Acquired Immunodeficiency Syndrome) \\ (H. Kofler, G. Schuler, P. Fritsch)}

\section{Definitionen}

AIDS. Eine - bei Ausbruch des Vollbilds - tödlich verlaufende Infektion mit dem Retrovirus HIV (human immunusuppressive virus), die durch Geschlechtsverkehr und Blut-Blutkontakt übertragen wird und eine sehr lange Latenzzeit hat. AIDS ist durch ein breites Spektrum klinischer Symptome gekennzeichnet, die entweder direkte Infektionsfolgen sind oder auf die Ausschaltung wesentlicher Teile des Immunsystems beruhen (opportunistische Infektionen, maligne Tumoren).

Retroviren. RNS-Viren, die ihre genetische Information in der Wirtszelle mittels eines spezifischen viralen Enzyms - der reversen Transkriptase - in doppelsträngige DNS umschreiben können.

Opportunistische Erreger. Solche, die nur bei Immunschwäche zur Erkrankung führen.

Allgemeines. AIDS ist eine „neue“ Krankheit, die derzeit nicht kausal behandelbar ist und nicht nur die medizinische Wissenschaft, sondern auch die Gesellschaft und das Gesundheitssystem mit schwierigsten Problemen konfrontiert. Deren hauptsächliche sind: die Kollision zweier hoher Rechtsgüter (Recht der Allgemeinheit auf Schutz vor Infektion und das des Individuums auf Schutz seiner Intimsphäre), die Verknüpfung von AIDS mit der Sexualsphäre (insbesondere der Homosexualität), der Drogensucht und auch der Kriminalität; schließlich die ungeheuren Kosten adäquater Diagnostik, Therapie und Pflege der Betroffenen sowie der Information der Öffentlichkeit. Wesentliche biologische Eigenschaften der HIV-Infektion sind: der lebenslange Verbleib des Virus im Wirtsgenom; die dadurch zumindest theoretisch gegebene lebenslange Infektiosität. Die sehr lange „Inkubationszeit“ (bis zu vielen Jahren). Der jederzeit mögliche Ausbruch von AIDS durch Aktivierung des Immunsystems - die geschätzte langfristige Wahrscheinlichkeit hiervon liegt zwischen 50 und $100 \%$. Die Häufigkeit neurologisch-psychiatrischer Symptomatik, die sehr häufig zu hoher Morbidität und erschwerter Infektionsprophylaxe führt. Schließlich der außerordentliche Polymorphismus des Virus, der die Aussichten auf eine Vakzine trübt.

Historisches. AIDS nahm nach einer gängigen Theorie in Zentralafrika seinen Ausgang und breitete sich über Haiti und die USA zu einer Pandemie 
aus. HIV entstand vermutlich durch Mutation eines tierischen Retrovirus (Visna-Virus? STLV-III-Virus? Ursprung: ,grüne Meerkatze“? Abb.81a). Die Infektion breitete sich wahrscheinlich durch Jahre unbemerkt aus, bis 1981 in den USA aufgrund gruppenweise gehäufter Krankheitsfälle AIDS als neue Krankheitseinheit definiert wurde. Entsprechend den Infektionswegen des HIV erfaßte die Pandemie zuerst die Homosexuellen (unter denen die Zahl der Personen mit zahlreichen Sexualpartnern höher ist als bei Heterosexuellen), die Prostituierten (gilt hauptsächlich für Entwicklungsländer), die Drogensüchtigen und die Hämophilen, beginnt aber zunehmend auf die Gesamtbevölkerung überzugreifen.

Der bevorzugte Tropismus des noch unbekannten Erregers für immunkompetente Zellen, deren Infektion zur Zerstörung des Immunsystems führt, lenkte den Verdacht auf eine seit Anfang dieses Jahrhunderts bekannte Virusfamilie: die Retroviren. 1983/84 gelang es zwei Arbeitsgruppen (Montagnier, Pasteur-Institut, und Gallo, NIH) aus dem Blut AIDS-kranker Patienten ein neues Retrovirus zu züchten, das sie LAV bzw. HTLV-III nannten. Hierauf ergaben sich in schneller Folge wesentliche Fortschritte: Einrichtung serologischer Nachweismethoden, Sequenzierung des Virusgenoms und Erprobung erster antiviraler Substanzen.

Erreger. Das Genom von HIV (Abb. 81 b) ist ca. 9 Kilobasen lang und besitzt Gene für Hüllproteine (env), gruppenspezifische Antigene (gag), reverse Transkriptase (pol) sowie mehrere kleinere Genabschnitte für „transaktivierende" Mechanismen (Regulation der Transkription und Translation: tat, art). RNS und reverse Transkriptase sind von core-Proteinen ummantelt. Aus der Virushülle (Envelope) ragen „Spikes“ (Hüllproteine, gp 120), die an bestimmte Oberflächenrezeptoren (T4) von Zielzellen binden und die Internalisierung des Virus auslösen (Abb. 81 c). Im Zellinneren verliert HIV Hülle und Kernproteine, die Virus-RNS wird mit der reversen Transkriptase in DNS umgeschrieben und diese zum Teil in das Genom der Wirtszelle integriert; das Virus kann hier als Provirus unbegrenzte Zeit verbleiben, bis die Aktivierung der infizierten Zelle zur Transkription von integrierter HIV-DNS und Produktion neuer, infektionsfähiger Viren führt.

HIV ist nicht sehr kontagiös (viel weniger als etwa das auf ähnlichem Weg übertragene Hepatitis-B-Virus), ist außerhalb des Körpers nur begrenzt lebensfähig (unter optimalen Bedingungen Tage) und wird leicht durch die gängigen Antiseptika abgetötet.

In letzter Zeit wurden in Westafrika, Amerika und Europa weitere, dem HIV verwandte Retroviren (HIV-2) nachgewiesen, deren Bedeutung derzeit noch nicht abschätzbar ist.

Pathogenese. HIV infiziert und zerstört Zielzellen über Bindung an den T4-Rezeptor, der von T4-Helfer/Inducer-Lymphozyten, Makrophagen, manchen Antigen-präsentierenden Zellen (Langerhans-Zellen), Gliazellen und B-Zellen exprimiert wird. Der primäre Schaden der HIV-Infektion betrifft den zellulären Schenkel des Immunsystems: Zirkulierende T-Helfer/Lymphozyten werden langsam depletiert (Lymphopenie). Dieser Schaden zieht 


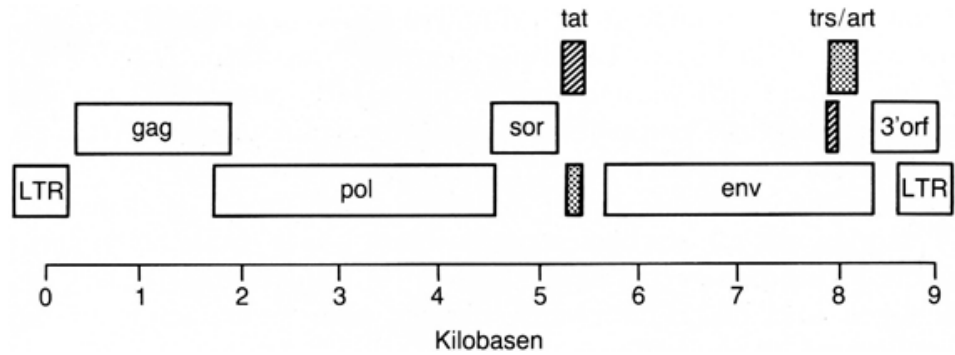

a

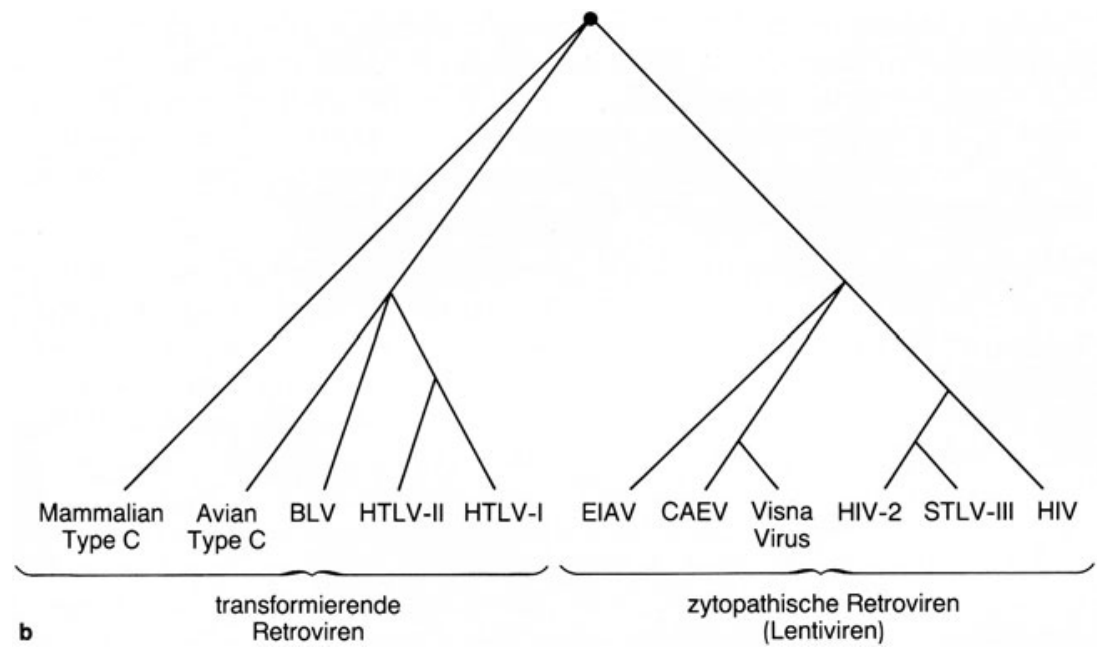

Abb.81. a, b

weitere Folgen durch Störung der Interaktion der Immunzellen nach sich: THelfer-Zellen kooperieren mit Makrophagen durch Freisetzung stimulierender Lymphokine (z. B. Gamma-Interferon). Eine Störung dieser Funktion ruft die häufig früh eintretende Anergie im Hauttest auf „Recall“-Antigene hervor. Analoge Gründe hat die Verminderung der Aktivität der Natural-killerZellen (Aufgabe: Tumorabwehr und Zerstörung virusinfizierter Zellen). BLymphozyten finden sich in normaler Zahl, doch ist ihre Funktion gestört (polyklonale Stimulierung der Antikörperproduktion mit Gamma-GlobulinErhöhung im Serum - vor allem IgG und IgA). Makrophagen können auch direkt infiziert werden; hieraus resultiert eine Reduktion ihrer Fähigkeit zur Phagozytose, Chemotaxis und Tötung intrazellulärer Erreger - z. B. Pneumo- 


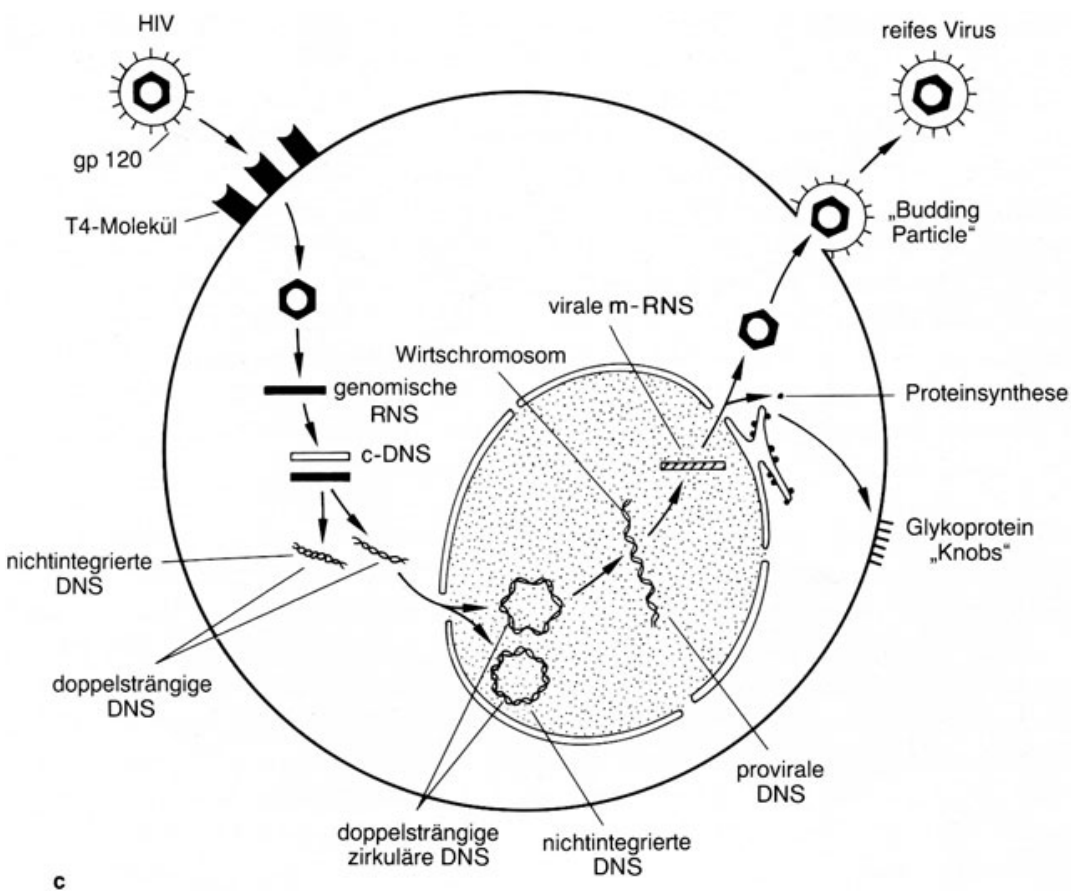

Abb.81 a HIV-Genom (siehe Text). LTR: Long terminal repeats. b Evolutionsschema der Retroviren. BLV: Bovine leukemia virus; HTLV-I, II: Human T-cell leukemia virus I, II; EIAV: Equine infectious anemia virus; CAEV: Caprine arthritis encephalitis virus. c Replikationszyklus des HIV (siehe Text). (Aus Ho, 1987)

cystis carinii, Toxoplasma. Infizierte Makrophagen und Monozyten können auch als Erregerreservoir wirken und die Infektion weiterverbreiten (ZNS). In vitro ist die Antwort sowohl auf T-Zell-abhängige (z. B. Pokeweed-Mitogen), als auch -unabhängige (z. B. Staphylokokkus aureus) Mitogene, in vivo auf Neoantigene deutlich vermindert.

Das Absinken der Immunlage geht vorerst subklinisch und meist sehr langsam vor sich, wobei akzidentelle Infektionen oder andere Belastungen des Immunsystems eine wesentliche Rolle spielen. Da die Virusreplikation in vitro durch Antigen-(Mitogen-)Zugabe stimuliert werden kann, vermutet man, daß eine Aktivierung der Zielzellen in vivo ähnliche Auswirkungen hat. Schließlich wird die Immunschwäche in Form opportunistischer Infektionen oder maligner Tumoren manifest. Von diesem Zeitpunkt an tritt gewöhnlich ein immer schneller ablaufender Circulus vitiosus auf (Infektion $\rightarrow$ Schwächung und gleichzeitig Aktivierung des Immunsystems $\rightarrow$ beschleunigte HIVReplikation $\rightarrow$ weiteres Absinken der Immunlage $\rightarrow$ neuerliche Infektionen), der schließlich mit dem Tod endet. 
Die häufige Entstehung maligner Tumoren wird mit einem Zweistufenmodell erklärt: Die Infektion mit HIV führt zur Immundefizienz und opportunistischen Infektionen. Der zweite Schritt ist die Induktion maligner Tumoren durch Ko-Faktoren, z.B. Epstein-Barr-Virus (EBV) und Zytomegalie-Virus (CMV) oder Herpes-simplex-Virus (HSV) (Neuinfektion oder endogene Reinfektion). Für diese Erklärung spricht, daß das Risiko einer Tumorentwicklung tatsächlich proportional zur Inzidenz dieser opportunistischen Infektionen ist. HSV- und CMV-Infektionen sind unter homosexuellen Männern weit verbreitet; bei ihnen tritt das Kaposi-Sarkom in fast $40 \%$ auf gegenüber $4 \%$ bei AIDS-Patienten aus anderen Risikogruppen. Eine ähnliche Beziehung zwischen der hohen Inzidenz von EBV-Infektionen bei AIDSPatienten und dem gehäuften Auftreten von (vor allem B-Zell-)Lymphomen ist plausibel.

Übertragung. HIV wird so gut wie ausschließlich durch Geschlechtsverkehr und Blut-Blutkontakt übertragen. Das höchste Infektionsrisiko kommt dem passiven Analverkehr zu (traumatisch); die Übertragung Frau $\rightarrow$ Mann scheint weniger häufig zu erfolgen als umgekehrt. Auf dem Blutweg wird HIV hauptsächlich durch intravenöse Drogenzufuhr bei gemeinsamem Gebrauch von Injektionsnadeln verbreitet. Eine heute durch Verbesserung der Herstellung und rigorose serologische Kontrollen fast ausgeschlossene Übertragungsmodalität ist die durch Bluttransfusionen und Blutprodukte. Durch kontaminierte Faktor-VIII-Präparate sind in den früheren Jahren die Hämophilenpopulationen zu einem hohen Teil (50-70\%) infiziert worden. Ein wesentlicher Übertragungsweg ist ferner die diaplazentare (bzw. perinatale) Infektion von Kindern infizierter Mütter.

- Merke: Übertragung durch Haut-Hautkontakt ist praktisch unmöglich. Auch Hautkontakt mit Tränenflüssigkeit und Speichel HIV-Infizierter ist wegen der geringen Menge enthaltener Viren ungefährlich. Selbst Stichverletzungen mit kontaminierten Nadeln etc. sind kein wesentlicher Infektionsweg (bislang sind nur einzelne derartige Fälle bekannt). Personen, die HIV-Infizierte betreuen (Haushaltskontakte, medizinisches Personal) haben also bei Beachtung der üblichen Vorsichtsmaßregeln ein sehr geringes Infektionsrisiko.

Epidemiologie. Die HIV-Infektion ist derzeit im wesentlichen noch auf bestimmte „Risikogruppen“ beschränkt: homo- oder bisexuelle Männer (mit ca. $70 \%$ der größte Teil der Infizierten), gefolgt von intravenös Drogenabhängigen (17\%). Das Geschlechtsverhältnis beträgt ca. 18:1 Männer zu Frauen (in Afrika annähernd 1:1; Infektion durch heterosexuellen Verkehr). Die Zahl der infizierten heterosexuellen Personen ist derzeit 2-4\%. In den USA ist ein Großteil der Geschlechtspartner infizierter Heterosexueller intravenös drogenabhängig.

Prävention. Mangels einer verfügbaren wirksamen Therapie zielen alle Bemühungen darauf $a b$, die Gruppe der Infizierten möglichst klein zu halten. Hauptinstrument der Prävention ist die Aufklärung, die die Idee des „safer 
sex" durchsetzen soll ( Verwendung von Kondomen, Vermeidung von Kontakt mit dem infektiösen Sperma etc.). Wie wirksam diese Maßnahmen sind, wird erst die Zukunft erweisen.

Mitte 1987 sind in den Vereinigten Staaten mehr als 38000 AIDS-Kranke bekannt, in Europa mehr als 4000, und eine nicht genau bekannte (aber sehr große) Zahl in Afrika. Die Zahl der asymptomatisch Infizierten wird um zwei Zehnerpotenzen höher angesetzt. Die Zunahme ist fast exponentiell, die Verdoppelungszeit liegt derzeit bei 12 Monaten. Ca. 15-38\% der Infizierten erkranken innerhalb von drei Jahren an AIDS, mindestens weitere $25 \%$ an milderen Krankheitserscheinungen (LAS, ARC). Möglicherweise werden diese Prozentsätze bei längerer Beobachtungszeit nach oben korrigiert werden müssen. Bei gleich schneller weiterer Ausbreitung rechnet man 1990 in Amerika mit fast 1 Million AIDS-Patienten (inklusive der Verstorbenen) und 5-10 Millionen Infizierten. In den europäischen Ländern muß mit einer zeitlich verschobenen, aber ähnlichen Entwicklung gerechnet werden. Die AIDS-Epidemie hat für die betroffenen Länder (inzwischen fast alle Staaten) weitreichende medizinische, soziale und ökonomische Konsequenzen. Vor allem arme afrikanische Länder mit einer hohen Zahl von Infizierten stehen vor fast unlösbaren Problemen.

Klinisches Bild. Das klinische Spektrum HIV-bedingter Krankheitsbilder ist fachüberschreitend und mannigfaltig. Im folgenden werden nur die wichtigsten und häufigsten davon dargestellt.

Bei einem Teil der Patienten entsteht 2-6 Wochen nach der HIV-Infektion ein initiales Mononukleose-ähnliches Frühsyndrom mit Fieber, konstitutionellen Symptomen, Lymphadenopathie und einem uncharakteristischen makulösen Exanthem. Nach Abklingen geht der Patient in eine oft jahrelange Latenzzeit über. Für die darauf folgenden Krankheitsstadien ist auch heute noch die klassische Einteilung (entsprechend den Definitionen des Center of Disease Control, Atlanta, USA) gültig:

1. Asymptomatische HIV-Infektion: HIV-Antikörper nachweisbar, subjektive und objektive Symptomlosigkeit.

2. Lymphadenopathie-Syndrom (LAS): Vergrößerung von Lymphknoten mindestens zweier extrainguinaler Lymphknotenstationen über mehr als drei Monate (ohne anderweitige erkennbare Ursache wie Toxoplasmose, Lymphom etc.).

3. AIDS related complex $(A R C)$ : Vorhandensein von mindestens zwei der folgenden subjektiven Beschwerden: Gewichtsverlust (mehr als 10\% des Körpergewichts), Nachtschweiß, Inappetenz, Diarrhoe, Leistungsabfall und mindestens zwei pathologischen Laborbefunden: Lymphopenie, Thrombopenie, Gamma-Globulin-Erhöhung, Hyp- oder Anergie im Hauttest, verminderte Zahl zirkulierender T-Helfer/Inducer-Zellen, verminderte T-Helfer/T-Suppressor-Zell-Ratio, und/oder das Auftreten milder opportunistischer Infektionen (z. B. Candidabesiedelung der Mundhöhle). 
4. AIDS: Erworbenes Immunmangelsyndrom (ohne andere faßbare Ursache als die HIV-Infektion). Dieses Vollbild der Krankheit ist wieder durch Symptome direkter Viruseinwirkung, zusätzlich aber durch Auftreten schwerer opportunistischer Infektionen und/oder maligner Tumore gekennzeichnet.

Direkte Viruswirkung: Bei ca. $60 \%$ stellen sich neurologisch-psychiatrische Veränderungen ein, zu deren schwerwiegendsten die Entwicklung einer Demenz zählt („AIDS-Enzephalopathie“). Hinzu kommen hämatologische (Autoimmunthrombozytopenie), renale (Proteinurie, fokale und segmentale Glomerulosklerose, akutes Nierenversagen), gastrointestinale (Diarrhoen), und pulmonale (lymphoztäre interstitielle Pneumonie) Erkrankungen.

Opportunistische Infektionen (Tabelle 12): Etwa 60\% der AIDS-Patienten erkranken an einer interstitiellen Pneumonie durch Pneumocystis carinii (häu-

Tabelle 12. Infektionen bei HIV-Infektion

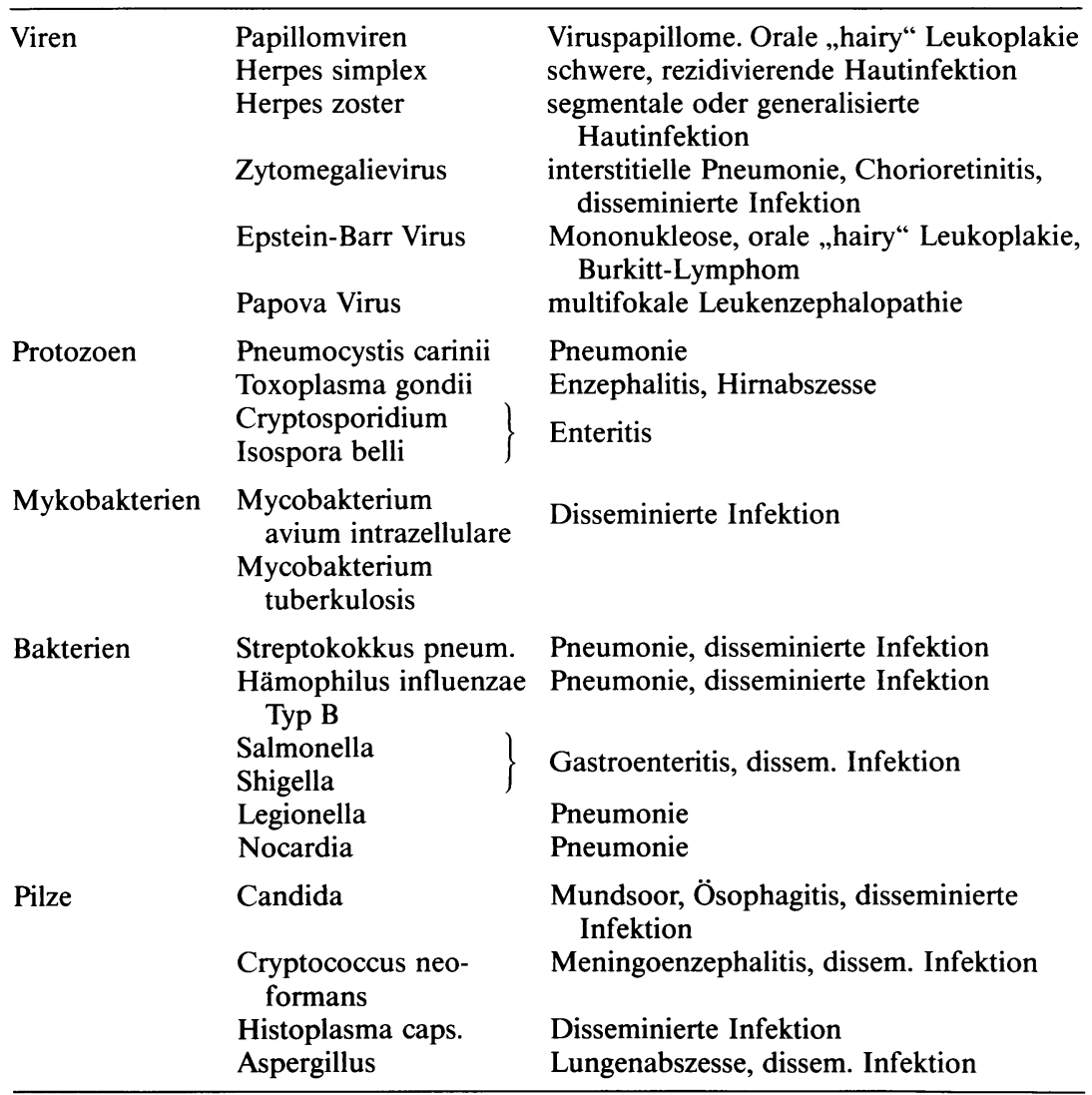


figste Todesursache). Am zweithäufigsten sind disseminierte Zytomegalievirusinfektionen mit Veränderungen an mehreren Organen (interstitielle Pneumonie, Colitis, Chorioretinitis - Gefahr der Erblindung). Kryptosporidiose oder Infektionen mit Isospora belli führen zu schwersten Diarrhoen. Im Gehirn kann es zur Ausbildung von Abszessen durch Toxoplasmose gondii, wie auch einer Meningoenzephalitis durch Cryptococcus neoformans kommen. An der Haut werden schwere, chronisch ulzerierende Verlaufsformen von Herpes simplex und Herpes zoster beobachtet. Immer häufiger werden ferner Tuberkulose und disseminierte Infektionen mit atypischen Mykobakterien (z. B. Mycobakterium avium-intrazellulare) mit Befall von Knochenmark, Lungen und Gastrointestinaltrakt diagnostiziert. AIDS-Patienten sind nicht nur einem hohen Risiko opportunistischer, sondern auch „normaler“ Infektionen ausgesetzt (Pneumonien durch Haemophilus influenzae und Staphylokokken, Salmonellen- und Shigellen-Sepsis).

Maligne Tumoren: Bei etwa 30\% aller AIDS-Patienten treten Kaposi-Sarkome auf, bei einem Teil gekoppelt mit opportunistischen Infektionen. Im

Tabelle 13. Häufige dermatologische „Leitsymptome“ bei HIV-Infektion

\begin{tabular}{|c|c|c|}
\hline & Erreger & \\
\hline Candidastomatitis & Candida albicans & $\begin{array}{l}\text { weißliche, wegwischbare Beläge, sel- } \\
\text { tener fleckiges Enanthem im Bereich } \\
\text { der Mundschleimhaut, sehr häufig } \\
\text { und früh beobachtbar; rezidiviert } \\
\text { häufig }\end{array}$ \\
\hline $\begin{array}{l}\text { „Seborrhoische“ } \\
\text { Dermatitis }\end{array}$ & Pityrosporum ovale? & $\begin{array}{l}\text { zentrofazial mit Betonung der Naso- } \\
\text { labialfalte, häufiges, frühes Zeichen } \\
\text { der HIV-Infektion }\end{array}$ \\
\hline $\begin{array}{l}\text { Orale „hairy“ } \\
\text { Leukoplakie }\end{array}$ & $\begin{array}{l}\text { Epstein Barr Virus? } \\
\text { Papillomviren? }\end{array}$ & $\begin{array}{l}\text { charakteristische, weißliche Hyperke- } \\
\text { ratose an den seitlichen Rändern der } \\
\text { Zunge }\end{array}$ \\
\hline Herpes simplex & H. simplex Virus & $\begin{array}{l}\text { oft ausgedehnte, ulzerierende Läsio- } \\
\text { nen mit protrahiertem Verlauf }\end{array}$ \\
\hline Herpes zoster & H.zoster Virus & segmental oder disseminiert \\
\hline Mollusca contagiosa & Pox. Virus & $\begin{array}{l}\text { an Prädilektionsstellen, aber auch } \\
\text { Gesicht, Stamm eruptives Auftreten } \\
\text { zahlreicher typischer Läsionen }\end{array}$ \\
\hline Kaposisarkom & $\begin{array}{l}\text { Zytomegalievirus als } \\
\text { Kofaktor wird } \\
\text { diskutiert }\end{array}$ & $\begin{array}{l}\text { Beginn mit unscheinbaren, lividen } \\
\text { Maculae und Knötchen; frühzeitig } \\
\text { multizentrisch, im Gegensatz zum } \\
\text { „klassischen“ Kaposisarkom rasche } \\
\text { systemische Ausbreitung. Prädilek- } \\
\text { tionsstellen: MSH, retroaurikulär, } \\
\text { Gesicht, Stamm, Genitale }\end{array}$ \\
\hline
\end{tabular}


Gegensatz zum „klassischen“ ist das „epidemische“ Kaposi-Sarkom bei AIDS-Patienten ein aggressiv wachsender Tumor mit frühzeitigem Befall von Schleimhäuten und inneren Organen. Überdurchschnittlich häufig kommt es auch zum Auftreten hochmaligner Lymphome, vor allem B-Zell-Lymphome mit raschem extranodalen Befall.

Merke: Hautsymptome sind bei AIDS häufig und von besonderer diagnostischer Bedeutung (Tabelle 13).

Serodiagnostik. HIV führt bei der überwiegenden Zahl der Infizierten zur Antikörperbildung, die in verschiedenen Testsystemen nachgewiesen werden kann. Als Suchtest wird der empfindliche Enzymimmunoassay (ELISA) eingesetzt. Prinzip: Mit Virusantigen beschichtete Mikrotiterplatten werden mit Serum inkubiert. In diesem enthaltene spezifische Antikörper binden sich an die Antigene; in einem zweiten Schritt wird mit einem enzymmarkierten Antihuman-Globulin inkubiert und das Ausmaß von dessen Bindung in einem letzten Schritt durch eine Enzym-mediierte Farbreaktion gemessen. Kürzlich entwickelte „Rekombinanten-ELISA's“ zeichnen sich durch eine höhere Spezifität aus, da genau definierte Antigene verwendet werden. Diese Tests zeigen in weniger als $1 \%$ falsch positive und in weniger als $3 \%$ falsch negative Resultate.

Ein im ELISA erhobenes positives Testergebnis muß in einem zweiten Testverfahren bestätigt werden: In der Regel geschieht das mit Hilfe der Westernblot-Technik, bei der Virusantigene (bzw. rekombinante Virusantigene) auf Nitrozelluloseazetatfolien aufgebracht und im elektrischen Feld nach dem Molekulargewicht aufgetrennt werden. Die Antikörperbindung wird wieder mit enzymmarkierten Antihuman-Antikörpern nachgewiesen. Der Westernblot erlaubt Aussagen darüber, gegen welche Virusantigene die Antikörper gerichtet sind (typische Banden liegen bei $24 \mathrm{Kd}, 41 \mathrm{Kd}, 55 \mathrm{Kd}, 64 \mathrm{Kd}$ und $120 \mathrm{Kd}$ ). Ein weiterer Bestätigungsnachweis ist die Immunfluoreszenz (Nachweis von an HIV-infizierten Lymphozyten gebundenen spezifischen Antikörpern mit FITC-markierten Antihumankonjugaten). In letzter Zeit wurden Enzymimmunoassays für Virusantigene entwickelt, die zur Überbrückung der Zeitspanne zwischen Infektion und Serokonversion dienen sollten; HIVAntikörper sind meist erst etwa 8-12 Wochen nach Infektion nachweisbar, Virusantigene jedoch schon früher. Ferner hat die Entwicklung geeigneter Methoden den kulturellen Nachweis von HIV aus verschiedensten Körperflüssigkeiten möglich gemacht. Nach ca. zweiwöchiger Kokultur sind die als Zielzellen verwendeten Lymphozyten (z. B. die Interleukin 2-abhängige H9-Zellinie) infiziert und replizieren neue HIV. Der Nachweis erfolgt durch Messung der reversen Transkriptase oder mittels radioaktiv markierter DNASonden, die mit passenden Nukleinsäuresequenzen des RNA-Virusgenoms hybridisieren. Der Virusnachweis ist aufgrund des hohen labortechnischen Aufwandes bestimmten Fragestellungen vorbehalten.

Therapie. Geeignete Chemotherapie der mit AIDS assoziierten Infektionen und malignen Tumoren ist zwar notwendig, nimmt aber keinen Einfluß auf den 
zugrundeliegenden immunologischen Defekt; der Patient bleibt gegen Rezidive der Infektionen und weitere Tumorentwicklung wehrlos. Therapeutische Überlegungen mit dem Ziel, den Immundefekt selbst zu beeinflussen, haben mehrere Angriffspunkte:

- Immunomodulation: Interleukin-2 - ein von aktivierten T-Helfer/InducerLymphozyten freigesetztes Lymphokin - spielt über Aktivierung des Effektorschenkels der Immunantwort (Natural killer-Zellen, zytotoxische T-Zellen) eine zentrale Rolle. Bei AIDS-Patienten ist die Produktion von Interleukin-2 defizient (T4-Lymphozyten sind verringert und funktionell defekt), folglich ist auch die Aktivität des Effektorschenkels reduziert. In vitro kann dieser Defekt durch Zugabe von Interleukin-2 teilweise aufgehoben werden, die klinische Verabreichung an AIDS-Patienten war jedoch enttäuschend. Das Risiko dieser Behandlung besteht darin, daß Interleukin-2 wieder Lymphozyten aktiviert und für eine Infektion durch HIV daher empfänglicher macht. Möglicherweise sinnvoller ist die Kombination von Interleukin-2 mit replikationshemmenden Substanzen. Eine andere immunmodulatorische Substanz, rekombinantes Alpha-Interferon, wird bei der Behandlung des Kaposi-Sarkoms mit teilweisem Erfolg eingesetzt (Remissionsraten zwischen 30 und 40\%). Eine Verbesserung immunologischer Parameter wurde bisher allerdings nicht beobachtet.

- Hemmung der Virusreplikation: Die Wirksamkeit einiger Hemmer der reversen Transkriptase (Suramin, HPA 23, Phosphonoformat) wurde zwar in klinischen Studien gezeigt, doch erwiesen sich diese Substanzen durch starke Nebenwirkungen als nicht brauchbar. Ribavirin interferiert mit neugebildeter viraler Messenger RNS und bewirkt, daß sie nicht vor zelleigenen Enzymen geschützt wird. Das bislang aussichtsreichste Präparat, Azidothymidin, ist ein Analog der Base Thymidin. Wird diese Base eingebaut, kann die Nukleinsäurekette nicht mehr verlängert werden, die HIV-Replikation wird unterbrochen. Klinische Studien haben eine ermutigende Wirksamkeit von Azidothymidin, aber auch schwere Nebenwirkungen aufgezeigt. Die Langzeittoxizität dieser Substanz ist derzeit noch Gegenstand von Untersuchungen. Ein Therapieversuch an einer nur kleinen Patientengruppe mit synthetisch hergestellten, doppelsträngigen RNS-Molekülen zeigte gutes Ansprechen und eine geringe Nebenwirkungsrate. Diese künstlichen RNS-Moleküle wirken über die Stimulierung von GammaInterferon in den befallenen Zielzellen und aktivieren körpereigene, RNS(retrovirale RNS)-abbauende Enzyme.

Klinische Bedeutung können antivirale Substanzen nur dann erlangen, wenn sie die Virusreplikationen auch in latent infizierten Zellen („Reservoirs") unterbinden, also imstande sind, durch die Blut-Hirnschranke zu penetrieren. Eine weitere Problematik ist, daß diese Substanzen zur Unterbindung der Infektion weiterer Zellen über lange Zeit, wahrscheinlich lebenslang, gegeben werden müßten. Die Entwicklung oral applizierbarer antiviraler Medikamente ohne oder mit geringer Langzeittoxizität ist daher erforderlich. 
- Impfstoffe: Die Herstellung wirft vielfältige, derzeit ungelöste Probleme auf. Die größte Schwierigkeit liegt im ausgeprägten Polymorphismus der Hüllproteine (gp41, gp120). Die Impfstoffentwicklung basiert auf folgender Überlegung: HIV infizierte Zellen tragen schon vor der Viruspropagation Virusantigen (Hüllproteine) an ihrer Zelloberfläche. Diese Antigenmarkierten Zellen sind Ziel einer möglichen, durch Impfung induzierten, Immunantwort; ihre Zerstörung verhindert die weitere Virusvermehrung. Freie Viruspartikel können gleichzeitig durch neutralisierende Antikörper inaktiviert werden. Klarerweise kann jedoch ein Impfstoff zwar gegen einen Subtyp wirksam, gegen einen anderen jedoch (Polymorphismus!) unwirksam sein. 